\title{
Ground motion characteristics of the Chi-Chi earthquake of 21 September 1999
}

\author{
Chin-Hsiung Loh ${ }^{1,2, \dagger}$, Zheng-Kuan Lee ${ }^{1, \ddagger}$, Tsu-Chiu $\mathrm{Wu}^{2, \|}$ and Shu-Yuan Peng ${ }^{1, \S}$ \\ ${ }^{1}$ National Center for Research on Earthquake Engineering, 200 Hsinhai Road, Section 3, Taipei, Taiwan \\ ${ }^{2}$ National Taiwan University, Taipei, Taiwan
}

\begin{abstract}
SUMMARY
The purpose of this paper is to investigate the ground motion characteristics of the Chi-Chi earthquake (21 September 1999) as well as the interpretation of structural damage due to this earthquake. Over 300 strong motion records were collected from the strong motion network of Taiwan for this earthquake. A lot of near-field ground motion data were collected. They provide valuable information on the study of ground motion characteristics of pulse-like near-field ground motions as well as fault displacement. This study includes: attenuation of ground motion both in PGA and spectral amplitude, principal direction, elastic and inelastic response analysis of a SDOF system subjected to near-field ground motion collected from this event. The distribution of spectral acceleration and spectral velocity along the Chelungpu fault is discussed. Based on the mode decomposition method the intrinsic mode function of ground acceleration of this earthquake is examined. A long-period wave with large amplitude was observed in most of the near-source ground acceleration. The seismic demand from the recorded near-field ground motion is also investigated with an evaluation of seismic design criteria of Taiwan Building Code. Copyright (C) 2000 John Wiley \& Sons, Ltd.
\end{abstract}

KEY WORDS: ground motion analysis; response spectrum; seismic demand analysis

\section{INTRODUCTION}

The Chi-Chi earthquake that occurred in Taiwan at 1:47 a.m. on 21 September 1999 directly struck the central part of Taiwan. The epicentre of the earthquake was at $23.85^{\circ} \mathrm{N}$ and $120.78^{\circ} \mathrm{E}$ with a focal depth of $7.5 \mathrm{~km}$ and magnitude $7.3\left(M_{\mathrm{L}}=7.3\right.$, Central Weather Bureau Earthquake

* Correspondence to: Chin-Hsiung Loh, National Center for Research on Earthquake Engineering, 200 Hsinhai Road, Section 3, Taipei, Taiwan

$\dagger$ Professor of Civil Engineering, National Taiwan University, Taipei, Taiwan, and also, Director, National Center for Research on Earthquake Engineering (NCREE)

* Associate Research Fellow

$\S$ Research Assistant, NCREE, Taipei, Taiwan

" Post-Doctor Researcher, National Science and Technology Program for Hazard Mitigation, National Taiwan University, Taipei, Taiwan

Copyright (C) 2000 John Wiley \& Sons, Ltd.

Received 17 November 1999

Revised 27 November 1999

Accepted 4 January 2000 
News). A surface rupture along the Chelungpu fault with a length of $105 \mathrm{~km}$ was observed. The largest measured vertical offset reached more than $9 \mathrm{~m}$. After the major shock a total of 10252 aftershocks were identified (till 10 October 1999). Among them four aftershocks with a magnitude greater than 6.5 were also identified. As a direct result of this earthquake, 2333 lives were lost and 10002 people were injured, and over 8000 buildings were damaged. On the basis of the number of dead, this was Taiwan's worst disaster since the Shin-Chu Taichung earthquake of magnitude 7.1 (21 April 1935) where 3325 lives were lost. This earthquake was the movement of Chelungpu fault (thrust fault) and the overhanging wall is on the east side of the fault.

Many buildings, including reinforced concrete buildings, were damaged but other facilities and structures such as bridges and lifelines were also damaged by this earthquake. The damage done by this earthquake in the central part of Taiwan is the first example of severe damage to civil infra-structures. The purpose of this paper is to study the ground motion characteristics of the Chi-Chi earthquake using the strong motion data collected by the Central Weather Bureau under the Taiwan Strong Motion Instrumentation Program (TSMIP). These analyses include: ground motion attenuation analysis, spectral amplitude study, principal direction and inelastic response analysis of a SDOF system subjected to this near-field ground motion.

\section{SEISMOLOGICAL AND GEOPHYSICAL DATA OF TAIWAN}

The island of Taiwan is located at a complex juncture between the Eurasian Plate and Philippine Sea Plate. North and east of Taiwan, the Philippine Sea Plate subducts beneath the Eurasian Plate to the north along the Ryukyu trench, while south of the island the Eurasian Plate underthrusts the Philippine Sea Plate to the east along the Manila trench. Taiwan can be divided into two major tectonic provinces, separated by a narrow, linear to geographic feature known as the longitudinal Valley $[1,2]$. The eastern province is interpreted as the leading edge of the Philippine Sea Plate in this area. The western province, which comprises the major part of the island, is associated with the Eurasian continental shelf. The western foothills have been stacked up by a combination of northwest vergent folds and low-angle thrust faults dipping to the southeast. Several large earthquakes have occurred in recent history. Figure 1 shows the active faults in Taiwan [3]. Three categories of fault are specified. Category I denotes the active fault, Category II denotes the less active fault, and Category III denotes the not-clear active fault. The Chelungpu fault belongs to the Category II. The Chi-Chi earthquake was caused by the rupture of Chelungpu fault. This earthquake is associated with a region only with relatively weak recent seismicity. The earthquakes triggered after the occurrence of Chi-Chi earthquake is shown in Figure 2 (with magnitude greater than 4.0) [4]. The Chelungpu fault was identified as the thrust fault with a dipping angle of $30^{\circ}$ to the east. The epicentres of the aftershock were located mostly on the east side of the fault.

In the seismic hazard analysis of Taiwan previously, the Chelungpu fault was not identified as the most active fault and the seismic hazard analysis (SHA) did not consider this fault as one of the active line source. It is necessary to consider this fault into re-evaluations of the seismic hazard map of Taiwan. Estimation of the earthquake occurrence rate on a fault requires the assumption of a fault model. For Chelungpu fault in this study the mechanics of faulting is described by the maximum magnitude model [5]. The average expected repeated time of earthquakes on a fault that is described by the maximum magnitude model can be 


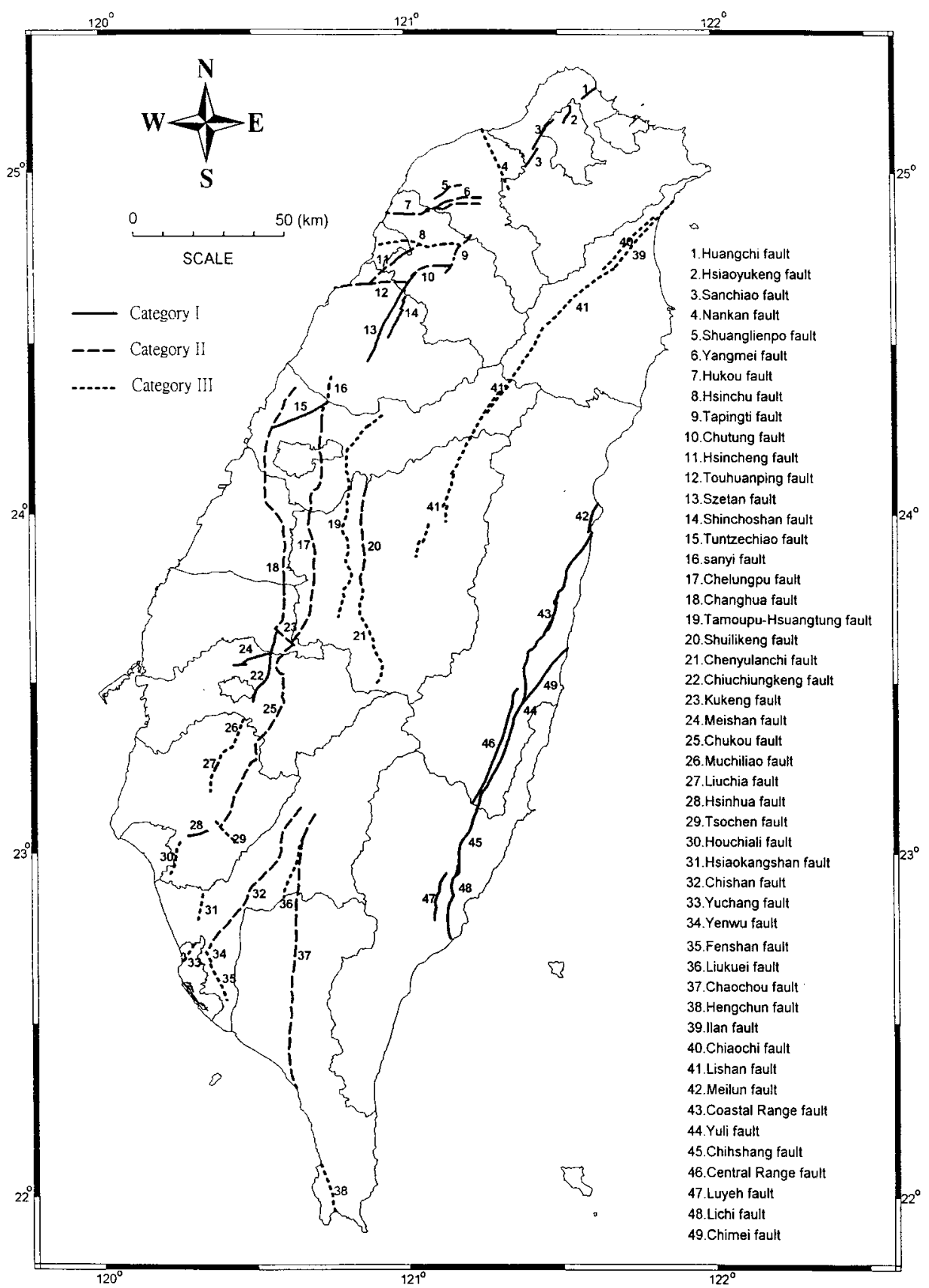

Figure 1. Identified active faults in Taiwan. Before 1999-9-21 Chi-Chi-earthquake Chelungpu fault was identified as category II. 


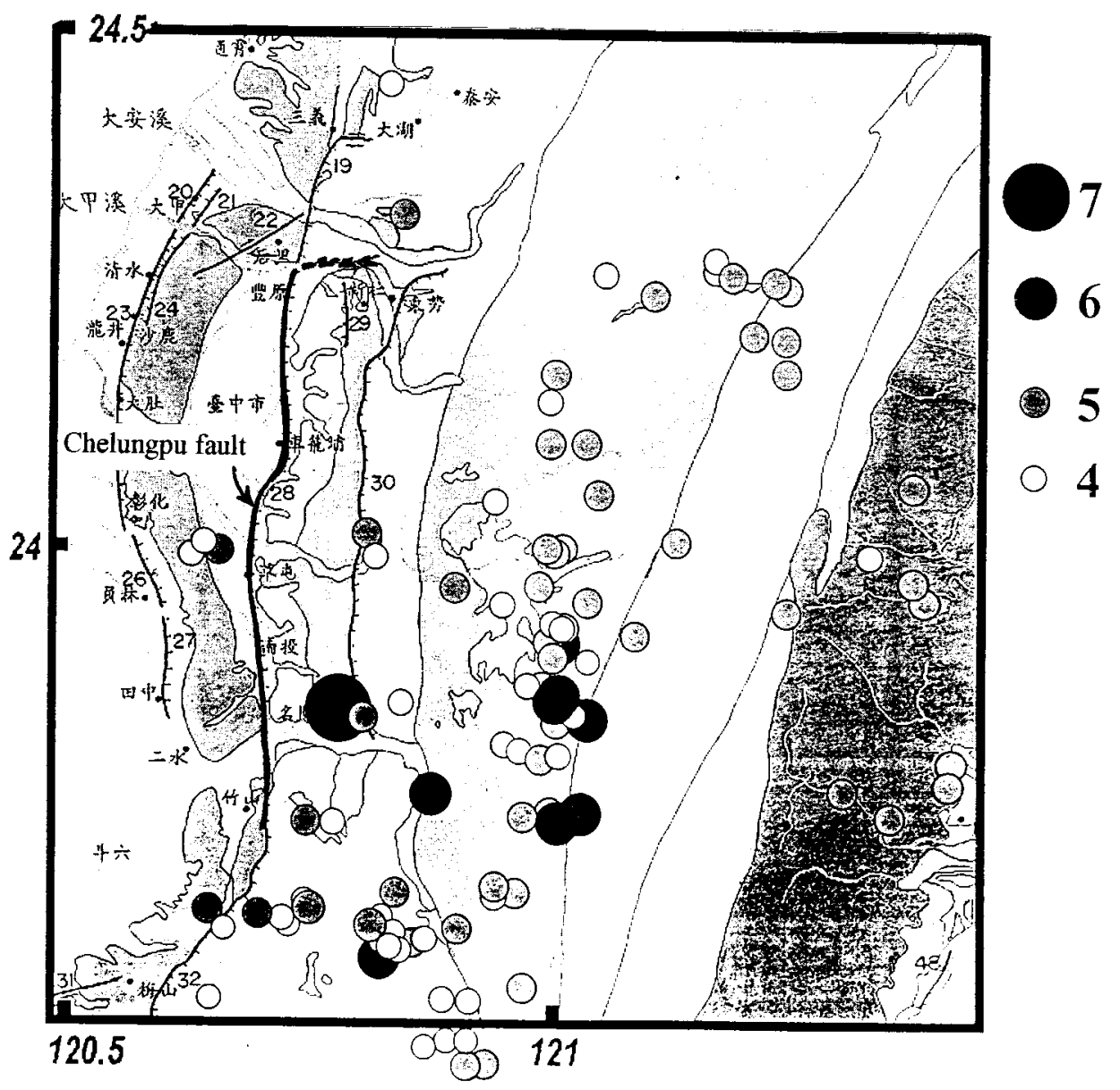

Figure 2. Epicenter of Chi-Chi earthquake and the distributor of aftershocks.

approximated to equal

$$
T=\frac{M_{0}^{\mathrm{c}}}{\dot{M}_{0}^{\mathrm{g}}}
$$

years, where the seismic moment $M_{0}^{\mathrm{e}}$ of the expected event on the fault is proportional to the fault length and the geologically assessed moment rate $\dot{M}_{0}^{\mathrm{g}}$ of the fault is a function of the fault slip rate. The moment rate $\dot{M}_{0}^{\mathrm{g}}=\mu l w u$ [6] of each fault is a function of the mapped fault length $l$ and the respective fault slip rate $u$, and the shear modulus $\mu\left(=3.0 \times 10^{11} \mathrm{dyn} / \mathrm{cm}^{2}\right)$ of the crust. The seismic moment $M_{0}$ can be estimated with the empirical relation $\log M_{0}=1.5 M+16.05$ [7] where $M$ is the moment magnitude. For the estimation of expected repeat time of Chelungpu 
fault, the following parameters are used:

\begin{tabular}{ccc}
\hline$M$ & (magnitude) & 7.5 \\
$\mu$ & (shear modulus) & $3 \times 10^{11} \mathrm{dyn} / \mathrm{cm}^{2}$ \\
$\dot{u}$ & (slip rate) & $0.2 \mathrm{~cm} / \mathrm{y}$ \\
$L$ & (length) & $8.0 \times 10^{6} \mathrm{~cm}$ \\
$W$ & (width) & $4.0 \times 10^{6} \mathrm{~cm}$ \\
$M_{0}^{\mathrm{e}}$ & (seismic moment) & $1.995 \times 10^{27} \mathrm{dyn}-\mathrm{cm}$ \\
\hline
\end{tabular}

Based on Equation (1) the estimated repeated time of Chelungpu fault is $1000 \mathrm{yr}$ (occurrence rate $=1.0 \times 10^{-3}$ ). This estimated repeated time depends on the estimation of slip rate $\dot{u}$. In this study $\dot{u}=0.2 \mathrm{~cm} / \mathrm{yr}$ was assumed (The rate of relative convergence between the Philippine Sea and Eurasian plates is about $6.8 \mathrm{~cm} / \mathrm{yr}$ [8]) and based on the width of the distribution of aftershock (as shown in Figure 2) $W=4.0 \times 10^{6} \mathrm{~cm}$ is assumed.

Since 1991 under the Taiwan Strong Motion Instrumentation Program (TSMIP), Central Weather Bureau (CWB) deployed over 600 seismometers on the island to collect free field ground motion data during earthquake. There are over 50 strong motion accelerometers along the Chelungpu fault, as shown in Figure 3, and many near-field ground motion data were collected during the main shock of Chi-Chi earthquake. Figures 4(a) and 4(b) show the recorded acceleration from stations along the fault, respectively. The velocity wave form was calculated from the acceleration data through baseline correction and integration process. The so-called pulse-like wave in the velocity wave form was also identified. Figure 5 shows the comparison between the calculated velocity from station TCU068, TCU102, TCU052, TCU075, CHY029, and CHY101 with the mathematical pulse-like wave. The type-A, type-B and type-C [9] near-field pulse-like waves can match the calculated velocity wave form collected along the Chelunpu fault very well. The duration of the pulse-like velocity wave form can be identified as high as $8.0 \mathrm{~s}$. This pulse-like wave may have significant influence on the seismic response of building structure.

\section{CHARACTERISTICS OF PGA AND PGV ATTENUATION}

Figure 6 shows the attenuation of the maximum horizontal peak ground acceleration (PGA) collected from each station with respect to its corresponded shortest distance $(D)$ from the fault plane (with dipping angle $30^{\circ}$ to the east). For this event over 25 records were collected within shortest distance of $10 \mathrm{~km}$. The regression line of PGA attenuation form for this event is shown in Table I. The Taiwan 'hard site' (i.e. with shear wave velocity greater than $250 \mathrm{~m} / \mathrm{s}$ ) PGA attenuation form is also shown in Figure 6 for comparison. The Taiwan 'hard site' PGA attenuation form was represented as [10]

$$
y(g)=0.02968 \exp [1.20 M]\left[R+0.1464 \mathrm{e}^{0.6981 M}\right]^{-1.7348}
$$

Comparison between the Taiwan 'hard site' PGA attenuation and the PGA attenuation of this earthquake indicated that the value of PGA attenuation form of Chi-Chi earthquake is smaller than the value of PGA attenuation of Taiwan 'hard site' form. It can be recognized from this figure that the PGA attenuation of Chi-Chi earthquake is not very peculiar except that three records with PGA value greater than $981 \mathrm{~cm} / \mathrm{s}^{2}$ were observed. The peak ground velocity 

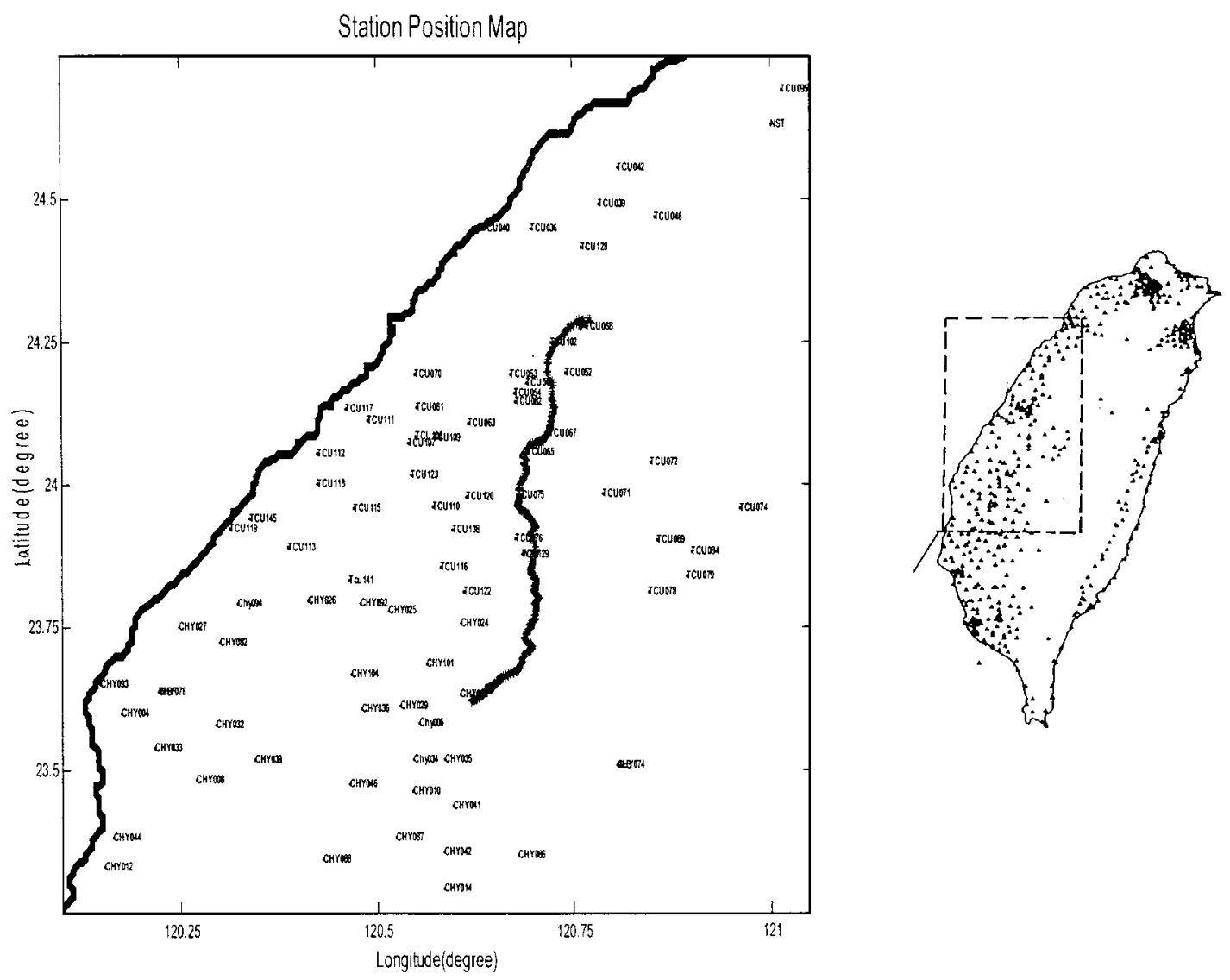

Figure 3. Distribution of strong motion instrumentation along Chelunpu fault. The TSMIP was developed by Central Weather Bureau.

attenuation formula for this earthquake is also analysed. Figure 7 shows the PGV attenuation formula for this earthquake. Table I shows the attenuation model and the model parameters for this event.

The contour map of PGA and PGV along the Chelungpu fault is shown in Figures 8(a) and 8(b), respectively. It is found that on the east side of Chelungpu fault the PGA value attenuates slower than the west side of the fault. The PGV-value distribution along the Chelungpu fault indicated that a larger value of PGV was observed at both ends of the fault.

Different from the plot of contour map by using the recorded value (either PGA or PGV-value) directly, a method to plot the PGA contour map is also introduced (the so-called 'shake map'). It is defined that the estimated PGA value at any station $j$ is expressed as

$$
\ln \mathrm{PGA}_{j}=\ln Y\left(\text { Dist }_{j}, \text { Site }_{j}\right)+\frac{\left(\sum_{i=1}^{N S T A} W\left(D_{i j}\right) \operatorname{Resid}_{i}\right)}{\left(1+\sum_{i=1}^{N S T A} W\left(D_{i j}\right)\right.}
$$


EW

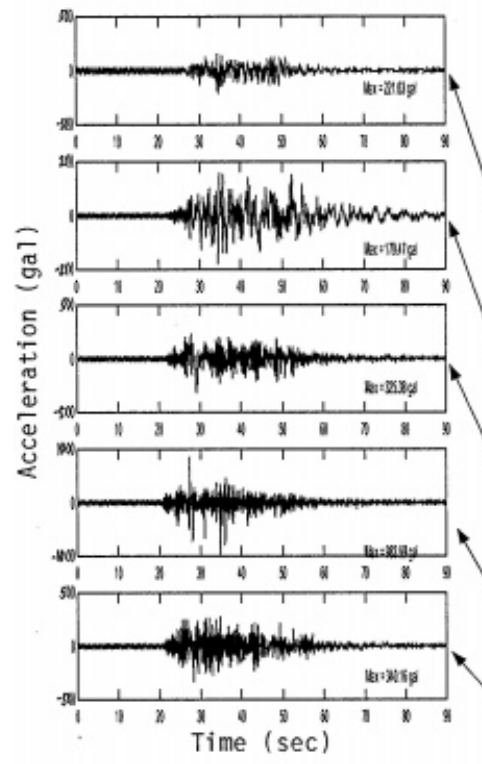

Acceleration

Time-History
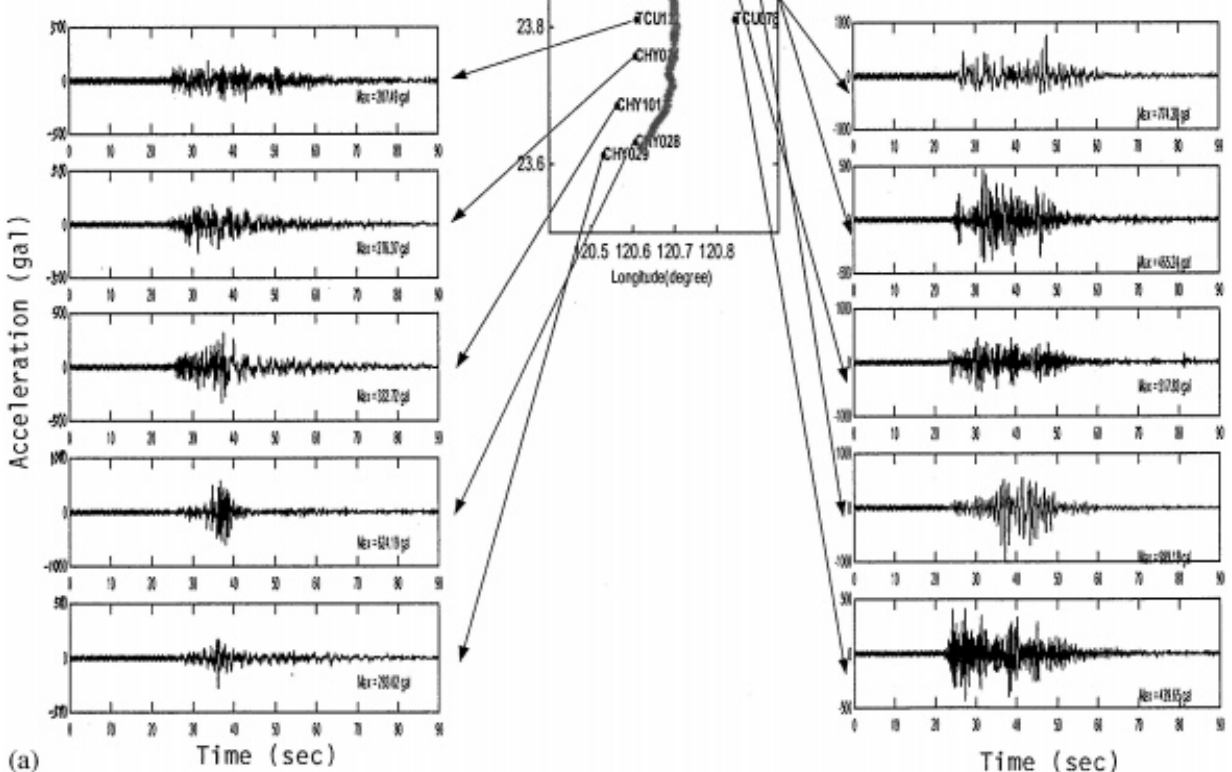

Figure 4. (a) Plot of recorded acceleration (in east-west direction) from stations along Chelungpu faults.

(b) Plot of recorded acceleration (in north-south direction) from stations along Chelungpu faults. 


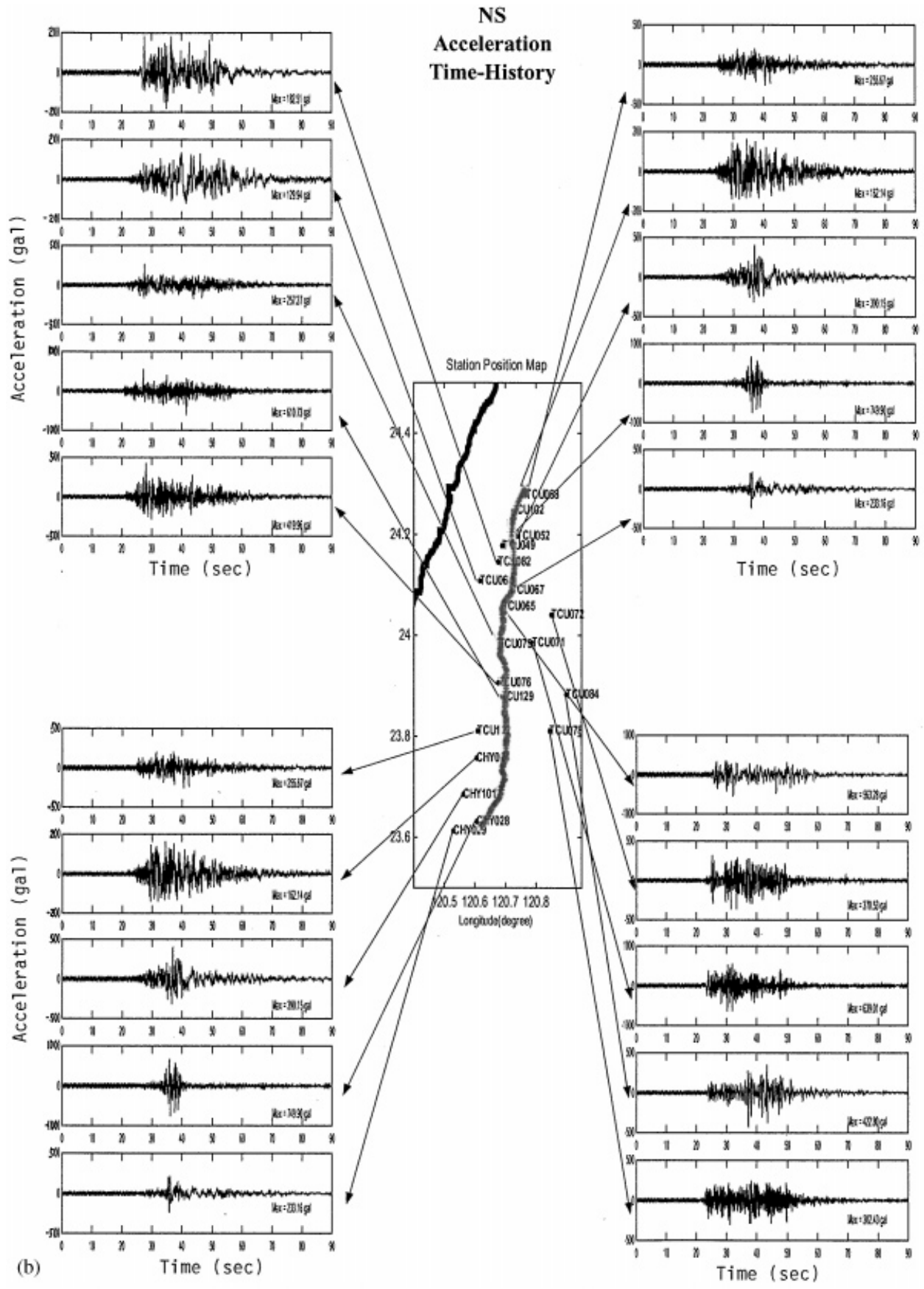

Figure 4. Continued. 

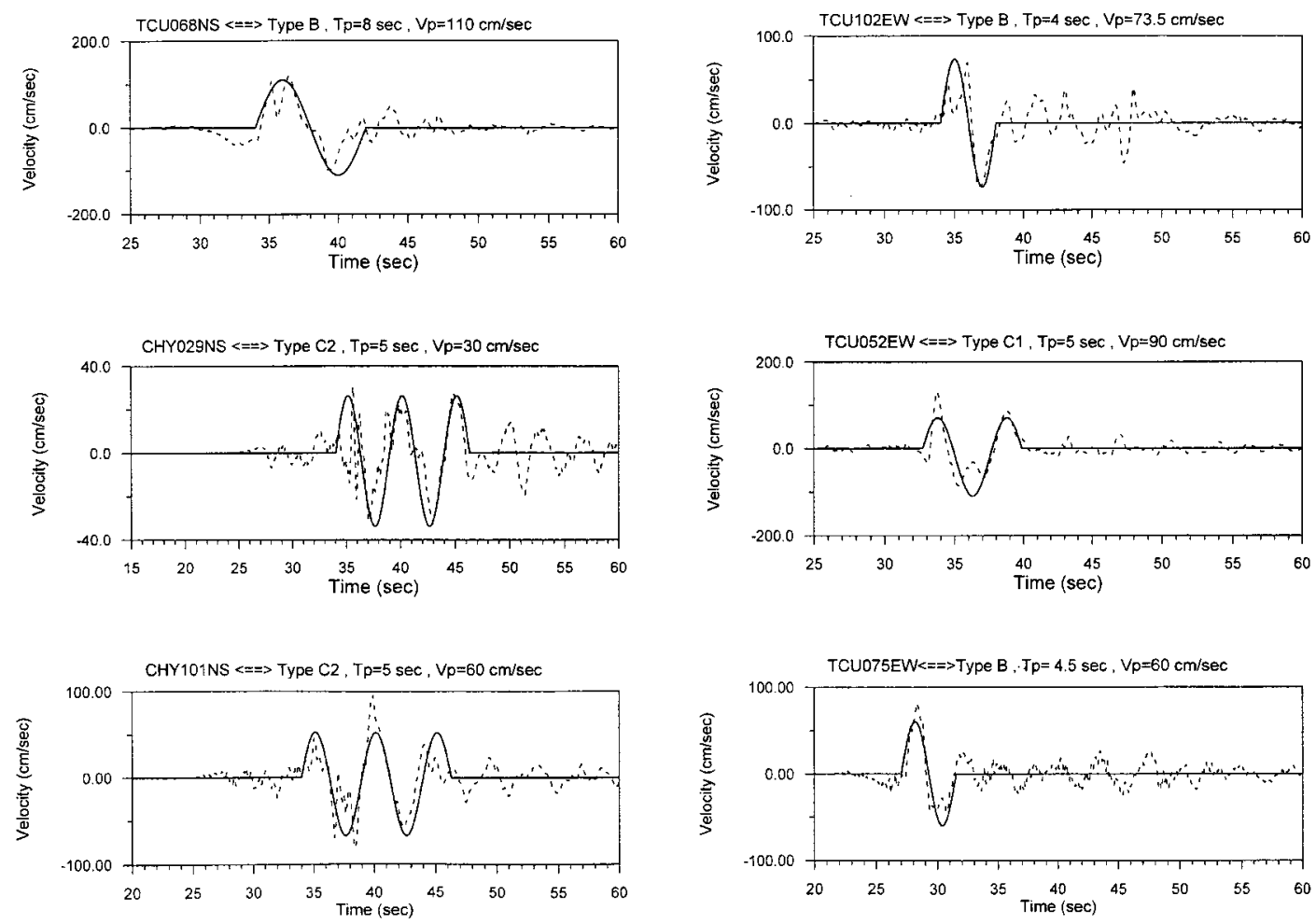

Figure 5. Comparison between the calculated velocity with the mathematical pulse-like wave (Type-B, Type-C1 and Type-C2) for station at TCU068, CHY029, CHY1101, TCU102, TCU052 and TCU075.

where

$$
W(D)=\left\{\begin{array}{cc}
\frac{1}{(D+0.1)} & \text { for } D<20 \mathrm{~km} \\
0.1 & \text { for } D>20 \mathrm{~km}
\end{array}\right.
$$

and $\ln Y\left(\right.$ Dist $_{j}$, Site $\left._{j}\right)$ is the estimated median PGA-value (from regression analysis of the recorded PGA-value). Dist ${ }_{j}$ denotes the distance at site $j$. $\operatorname{Resid}_{i}$ is the residual (difference between recorded value and regression value) for station $i$. Figure 9 shows the shake map of PGA-value (using geometric mean of two horizontal PGA values) by applying the regression form from Table I. The ratio between horizontal PGA and vertical PGA is also studied. Figure 10 shows the change of ratio with respect to the shortest distance. It is observed that the ratio between the horizontal PGA and vertical PGA is about 1.5 at a distance close to the fault. At the northern tip of the Chelungpu fault, particularly at station TCU068, the vertical PGA-value is greater than the horizontal PGA-value. 

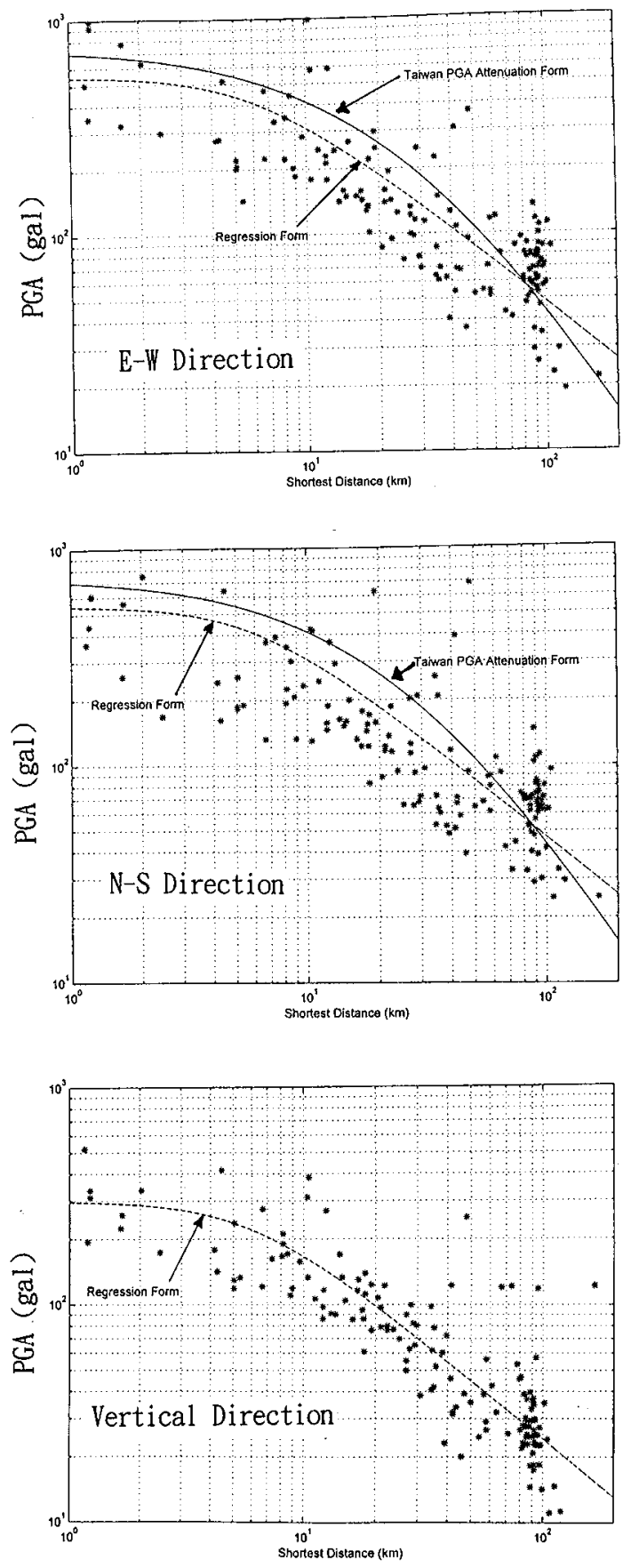

Figure 6. Attenuation of peak ground acceleration for 1999-9-21 earthquake in east-west, north-south and vertical direction. The dash line represents the regression line from data of the Chi-Chi earthquake and the solid line represents the Taiwan 'hard site' attenuation form (without consideriong the data of Chi-Chi earthquake). 
Table I. Identified model parameters for PGA and PGV attenuation form.

\begin{tabular}{cccccc}
\hline \multicolumn{5}{c}{$\ln$ PGA $\left(\mathrm{cm} / \mathrm{s}^{2}\right)$} & \multicolumn{5}{c}{$C_{1}+C_{2}(m-6)+\left[C_{4}+C_{5}(m-6)\right] \ln \left(R^{2}+C_{6}^{2}\right)^{1 / 2}$} \\
\hline & $C_{1}$ & $C_{2}$ & $C_{4}$ & $C_{5}$ & $C_{6}$ \\
\hline EW-direction & 8.7482 & -0.6829 & -1.3397 & 0.3645 & 6 \\
NS-direction & 8.7574 & -0.6760 & -1.3479 & 0.3628 & 6 \\
Up-down direction & 7.8809 & -0.4428 & -1.5474 & 0.5025 & 6 \\
\hline \multicolumn{7}{c}{$\ln$ PGV $(\mathrm{cm} / \mathrm{s})=$} & $C_{1}+C_{2}(m-6)+\left[C_{4}+C_{5}(m-6)\right]$ & $\ln \left(R^{2}+C_{6}^{2}\right)^{1 / 2}$ & \\
\hline \multicolumn{7}{c}{$C_{1}$} & $C_{2}$ & $C_{4}$ & $C_{5}$ & $C_{6}$ \\
\hline EW-direction & 6.2693 & -0.6015 & -1.2842 & 0.4721 & 6 \\
NS-direction & 6.2903 & -0.744 & -1.2535 & 0.4683 & 6 \\
Up-down direction & 6.2047 & -0.7672 & -1.2205 & 0.3439 & 6 \\
\hline
\end{tabular}

\section{ANALYSIS OF PRINCIPAL DIRECTION AND RESPONSE SPECTRUM}

\section{Principal direction analysis}

The principal direction of the recorded ground motion along the Chelungpu fault is calculated using the method developed by Loh [11]. Based on this technique, the variance-covariance matrix is calculated from the three-orthogonal ground acceleration data at a station. The direction of principal axis is the calculated eigenvector from the variance-covariance matrix. Figure 11 shows the major principal axis calculated from the data collected near the Chelungpu fault. It is found that the major principal axis of ground motion from stations near Chelungpu fault is almost perpendicular to the fault. It consists the larger PGA value in east-west direction than in north-south direction and the frontal thrust fault in the east.

\section{Response spectrum analysis}

Linear response spectral analysis was also studied. Figures 12(a)-(d) show the calculated acceleration response spectrum $\left(S_{\mathrm{a}}\right)$ and the velocity response spectrum $\left(S_{\mathrm{v}}\right)$ from the data along the fault line. The contour map of spectral acceleration $S_{\mathrm{a}}$ at period $T=0.6$ and $1.2 \mathrm{~s}$ is shown in Figure 13(a) and spectral velocity $S_{\mathrm{v}}$ at period $T=1.2$ and $4.0 \mathrm{~s}$ is shown in Figure 13(b). A large amplitude of spectral acceleration was observed at the east side of the fault line on the contour map of $S_{\mathrm{a}}$-value in the east-west direction at $T=0.6 \mathrm{~s}$. A large amplitude of spectral acceleration was also observed at both ends of the fault line on the contour map of $S_{\mathrm{a}}$-value in north-south direction at $T=0.6 \mathrm{~s}$. Even at $T=1.2 \mathrm{~s}$ a large amplitude of spectral acceleration was also observed (as shown in Figure 13(b)). From the spectral velocity contour map along Chelungpu fault a large value of spectral velocity was observed, as shown in Figure 14. It has to be pointed out that even at $T=4.0 \mathrm{~s}$ very large $S_{\mathrm{v}}$-value was estimated on both ends of the fault (as shown in Figure 14(b)). The velocity spectral amplitude $\left(S_{\mathrm{v}}\right)$ attenuation form for each structural period is also shown in Figure 15. This large $S_{\mathrm{v}}$-value may be due to the effect of near-field ground motion. Table II listed the identified model parameters of the spectral amplitude attenuation form. 

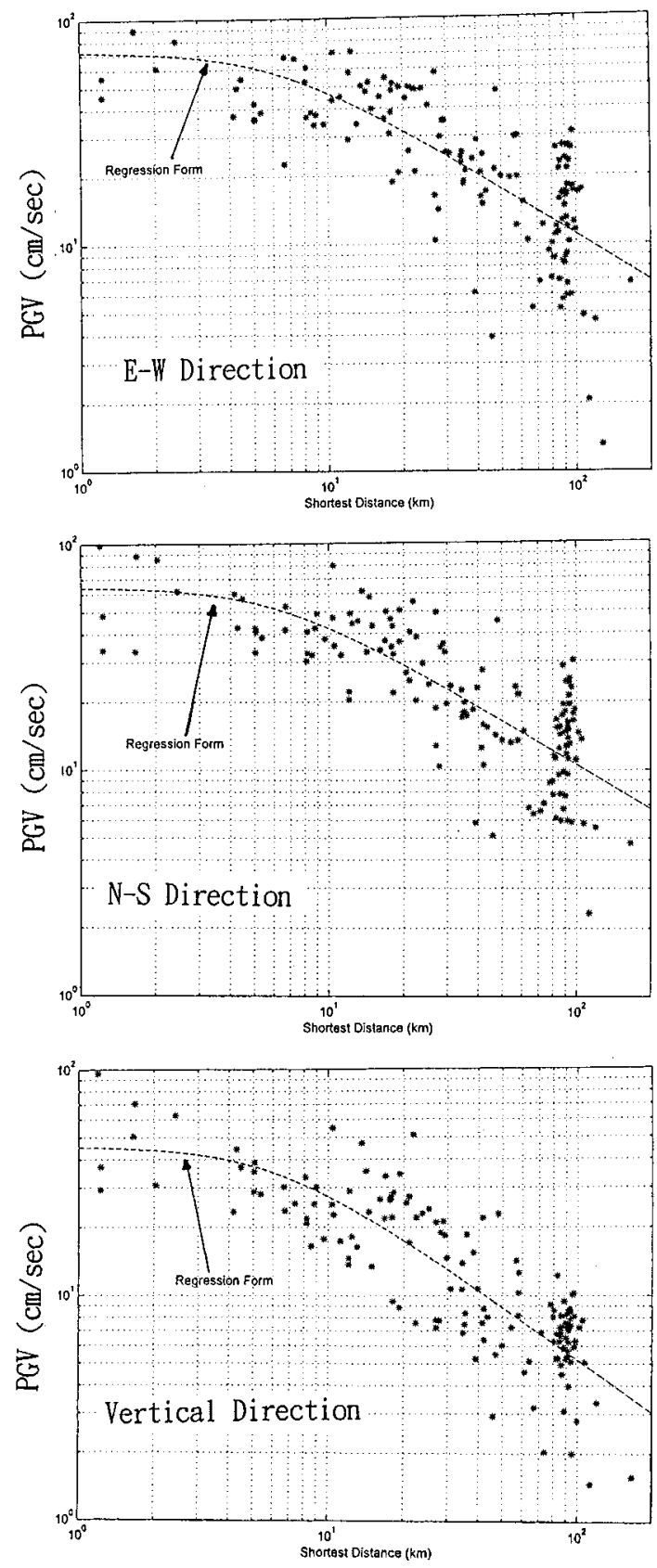

Figure 7. Peak ground velocity attenuation for 1999-9-21 earthquake in east-west direction, north-south direction and vertical direction. 

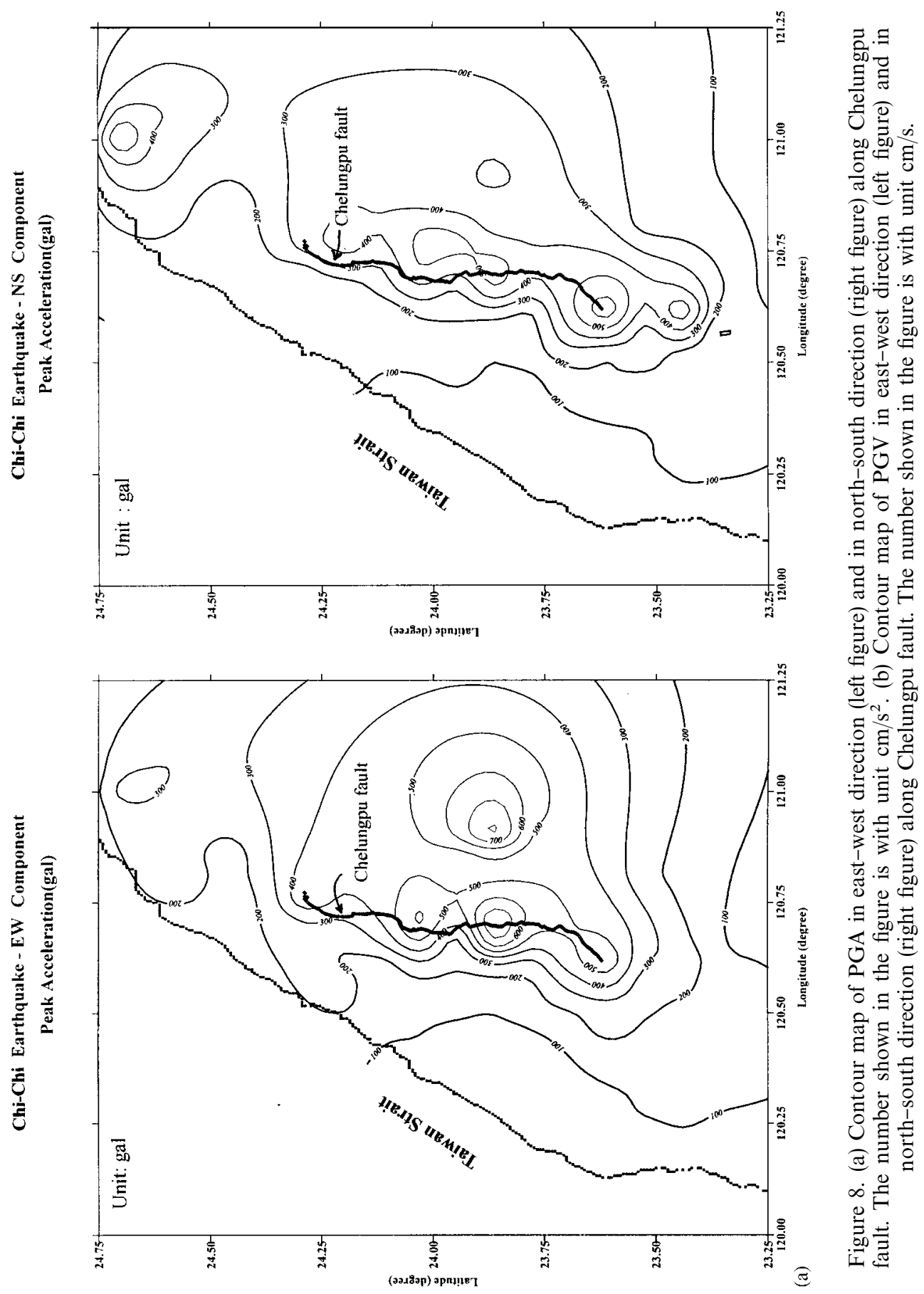


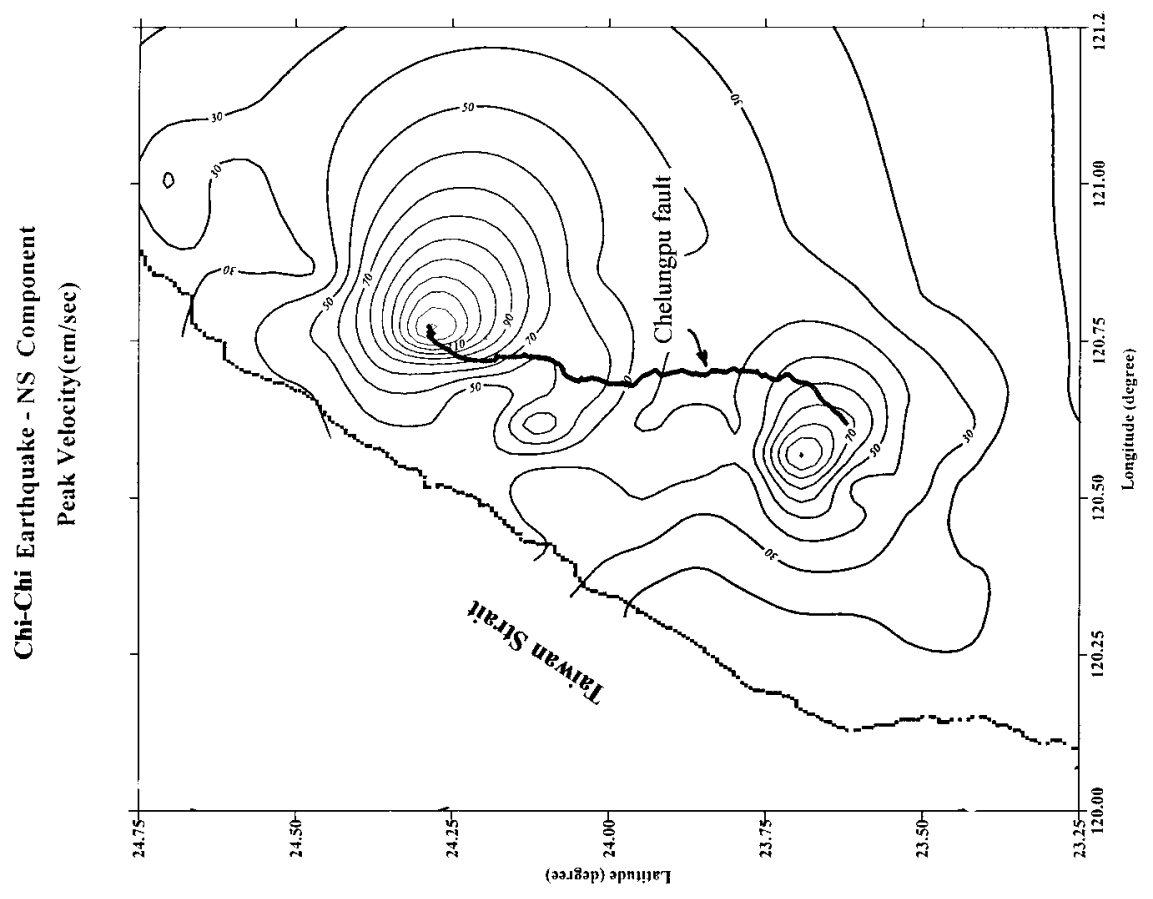

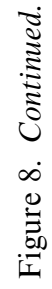

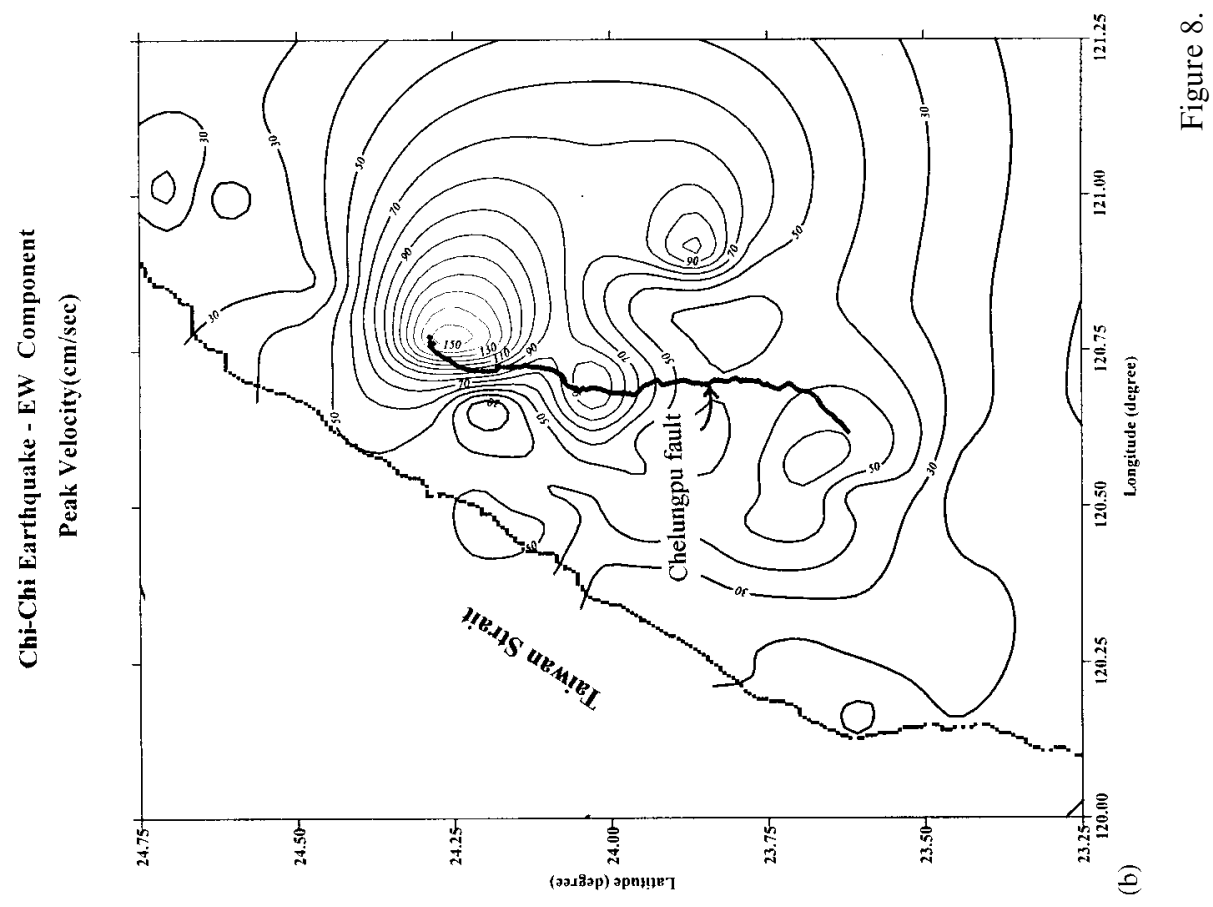




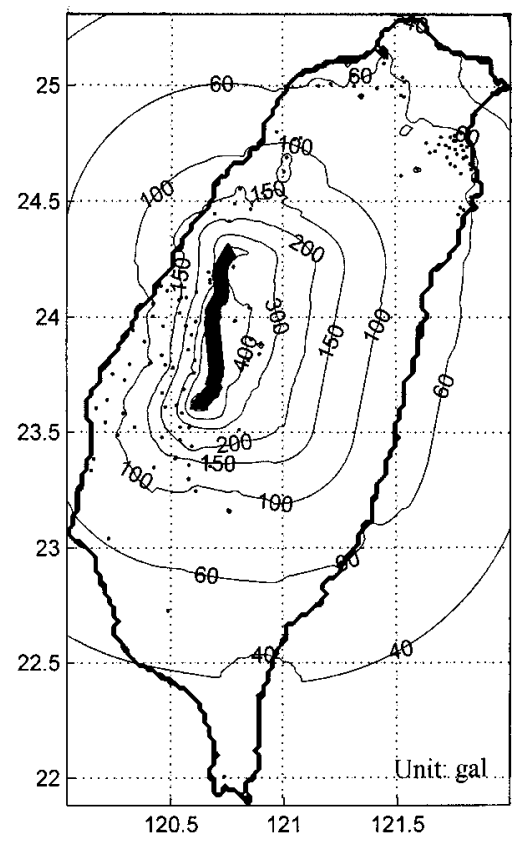

Figure 9. Shake map for the Chi-Chi earthquake (using geometric mean of both two horizontal components).

\section{Spectral ratio analysis}

To compute the spectral ratio of the response spectra for 5 per cent of critical damping, the vertical-to-horizontal $(\mathrm{V} / \mathrm{H})$ response spectral ratio is discussed. Figure 16 shows the $\mathrm{V} / \mathrm{H}$ spectral ratio for data along the Chelungpu fault. Generally the $\mathrm{V} / \mathrm{H}$ spectral ratio will have a value greater than one on the smaller range of structural period and less than one on the range of large structural period. Figure 16 indicates that the $\mathrm{V} / \mathrm{H}$ ratio from the data of Chi-Chi earthquake did not follow the same trend as the general trend. More detail analysis on the vertical to horizontal spectral ratio must be done from these near-field ground motion data.

\section{EMPIRICAL MODE DECOMPOSITION ANALYSIS}

Based on the results of acceleration response spectrum analysis, it is found that the ground motion collected near Chelungpu fault is quite different because of the rupture process of the fault and the site condition. It is known that the earthquake ground motion is a highly non-stationary random process. It is difficult to recover the low-amplitude long-period seismic wave (greater than 2 or $3 \mathrm{~s}$ ) from the recorded data with traditional Fourier analysis. The effect of this long-period wave to structural response was generally neglected by engineering design. The empirical mode decomposition method provides a powerful technique to identify the 

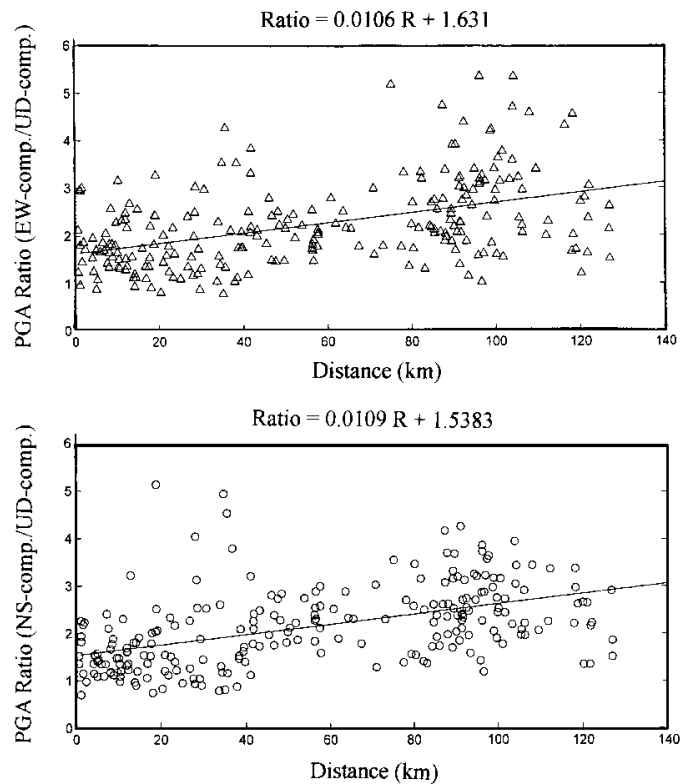

Figure 10. Variation of horizontal PGA to vertical PGA ratio with respect to Distance.

non-stationary data, particularly the earthquake ground motion. This decomposition method was proposed by Huang et al. [12]. Through the application of the method the fundamental period of the ground motion can be identified. A brief description of the method is discussed.

Consider an original ground acceleration $\ddot{x}(t)$, one may perform the following mathematical operation:

$$
h_{11}(t)=\ddot{x}(t)-m_{11}(t)
$$

where $m_{11}(t)$ is the mean value of the lower and upper envelops for $\ddot{x}(t)$. Next, make the same shifting procedure for $h_{11}(t)$, that is

$$
h_{12}(t)=h_{11}(t)-m_{12}(t)
$$

Keeping the same shifting procedure until $h_{1 k}(t)$ converges, the sub-channel signal $c_{1}(t)$ is defined as follows:

$$
C_{1}(t)=h_{1 k}(t)
$$

Thereafter, the residue signal $r_{1}(t)$, which is equal to $\ddot{x}(t)$ minus $c_{1}(t)$ is treated as a new data and subjected to the same shifting process described above. Then another sub-channel $c_{2}(t)$ is generated. Repeating those procedures, eventually, the original $\ddot{x}(t)$ is decomposed as follows:

$$
x(t)=\sum_{j=1}^{n} c_{1}(t)+r_{n}(t)
$$




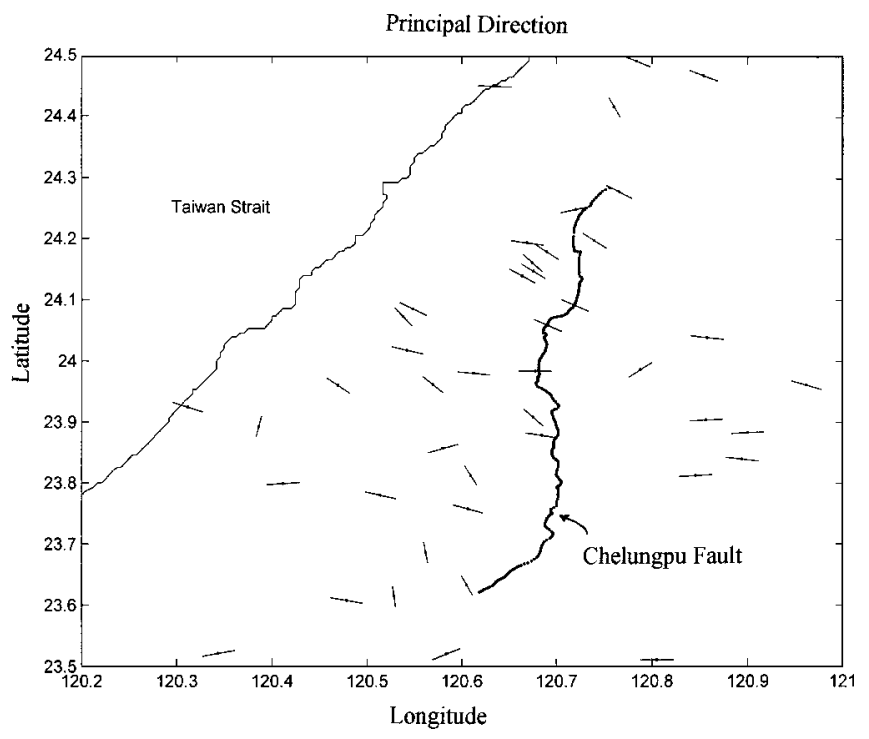

Figure 11. Plot of the principal direction from recorded acceleration along Chelungpu fault.

The summation indicates that a total of $n$ intrinsic model functions are decomposed. Through the empirical mode decomposition method, the intrinsic seismic wave can be decomposed and the long-period wave from the original data can also be identified.

In this study, the empirical mode decomposition method was used to identify the dominant period from seismic response data collected along the Chelungpu fault for 1999-9-21 earthquake. To emphasize the dominant period of the decomposed wave, one can calculate the Fourier amplitude spectrum from each intrinsic mode function (IMF). Figure 17 shows the decomposed ground acceleration (intrinsic mode function) at station TCU129 (at the center of Cheluinpu fault) and the Fourier amplitude spectrum of each decomposed wave. Through the Surfer software the contour map of the PGA for each decomposed wave is plotted along Chelungpu fault at different frequency band, as shown in Figure 18. Figures 18(a) and 18(b) show the contour map of PGA (both EW-direction and NS-direction) for frequency band between 0.5 and $0.8 \mathrm{~Hz}$ and between 1.0 and $1.4 \mathrm{~Hz}$, respectively. It is found that at the low-frequency band, 0.5 and $0.8 \mathrm{~Hz}$, the PGA-value with 120 gal was observed, and at a frequency band of 1.0 and $1.4 \mathrm{~Hz}$ the PGA value with 200 gal was also observed. From this analysis it is clear that even at low-frequency band a very large ground acceleration was observed.

\section{INELASTIC RESPONSE ANALYSIS - SEISMIC DESIGN PARAMETERS}

The Taiwan seismic design building code for base shear force is expressed as [10]:

$$
V=\frac{Z I}{\Omega \alpha_{\mathrm{y}}}\left(\frac{C}{F_{u}}\right) W=C_{\mathrm{d}} \cdot W
$$




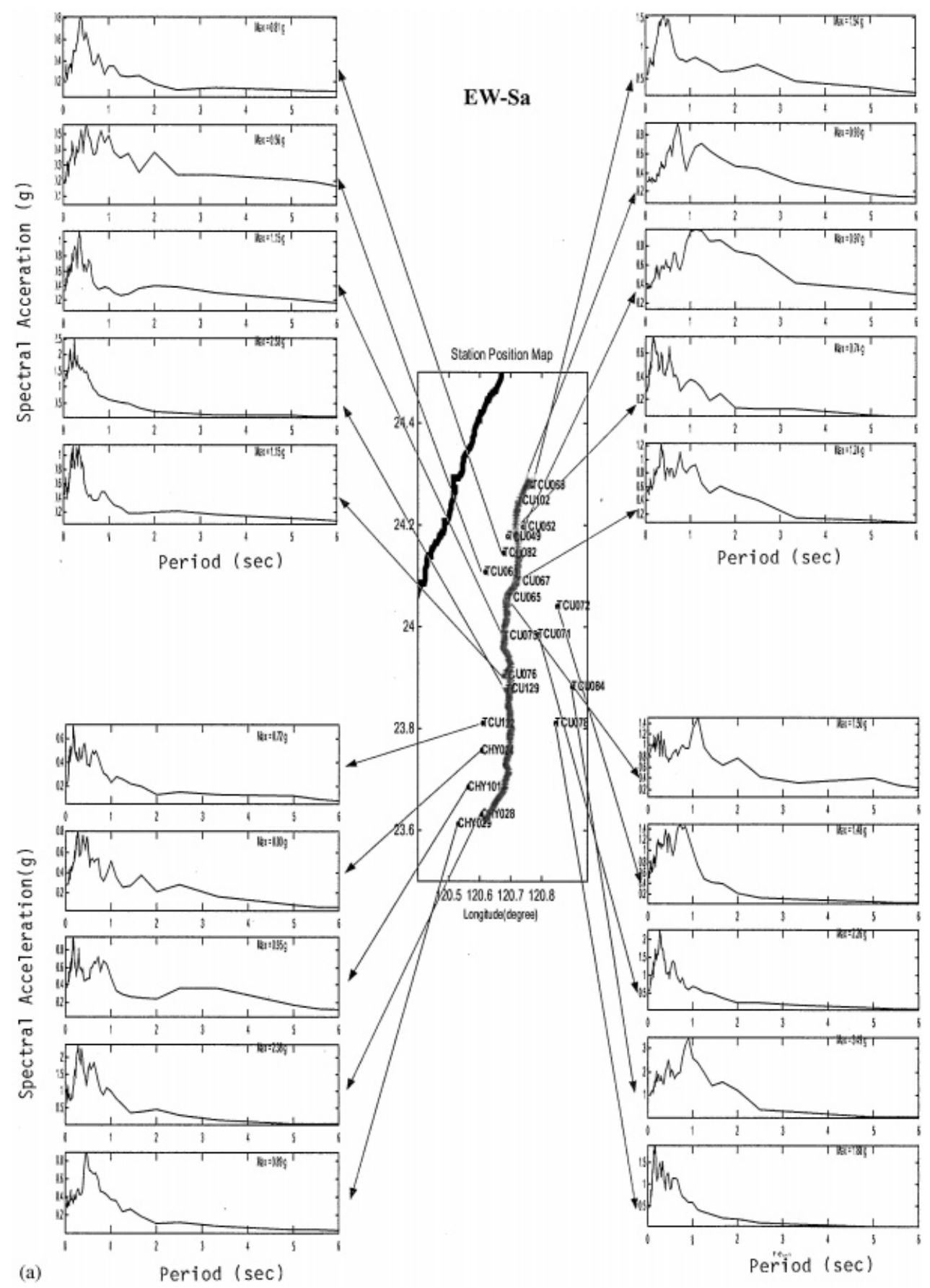

Figure 12. (a) Plot of acceleration response spectrum $\left(S_{\mathrm{a}}-5 \%\right)$ from acceleration data in east-west direction along Chelungpu fault. (b) Plot of acceleration spectrum $\left(S_{\mathrm{a}}-5 \%\right)$ from acceleration data in north-south direction along Chelungpu fault. (c) Plot of velocity response spectrum $\left(S_{\mathrm{v}}-5 \%\right)$ from acceleration data in east-west direction along Chelungpu fault. (d) Plot of velocity response spectrum $\left(S_{\mathrm{v}}-5 \%\right)$ from acceleration data in north-south direction along Chelungpu fault. 


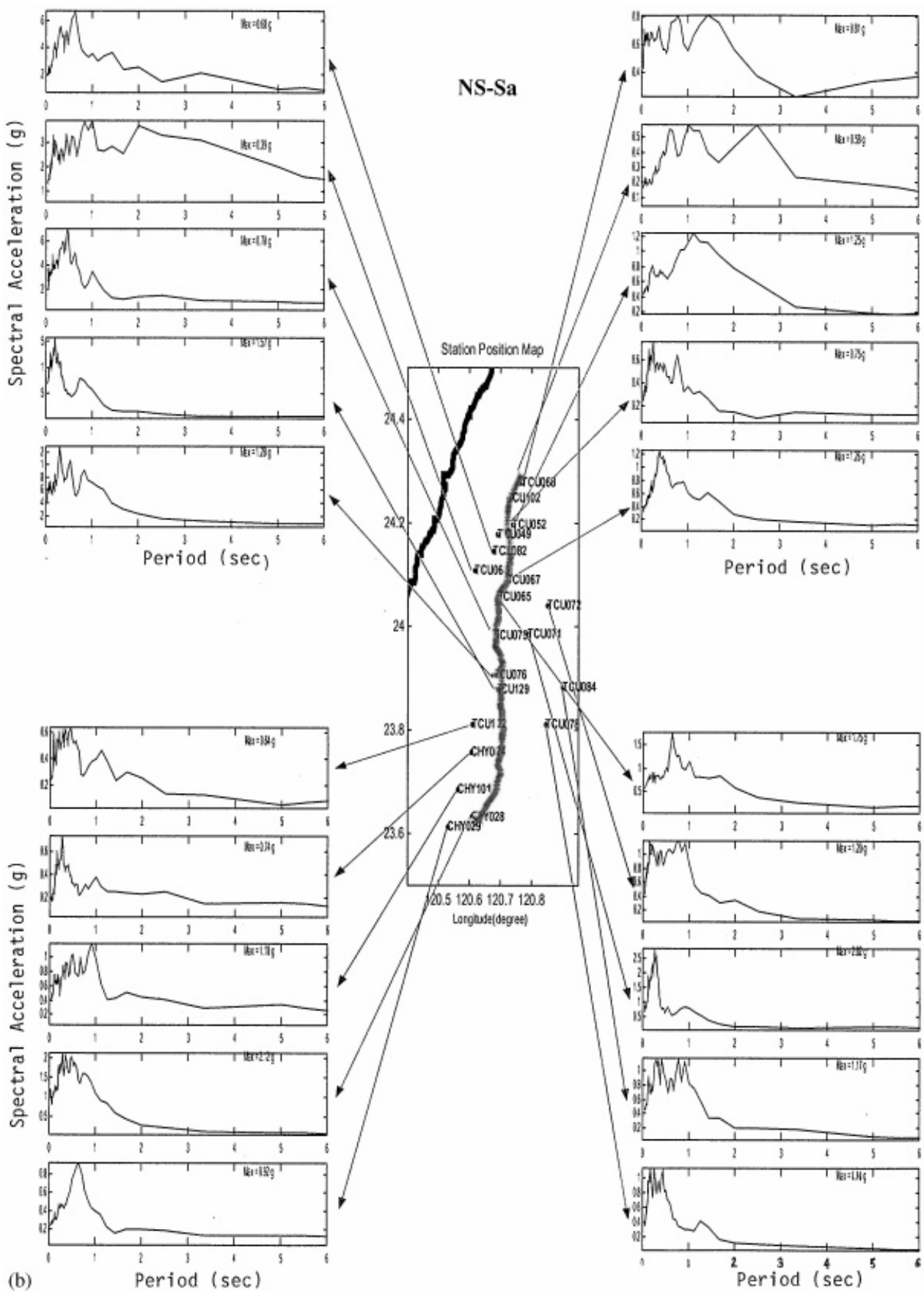

Figure 12. Continued. 


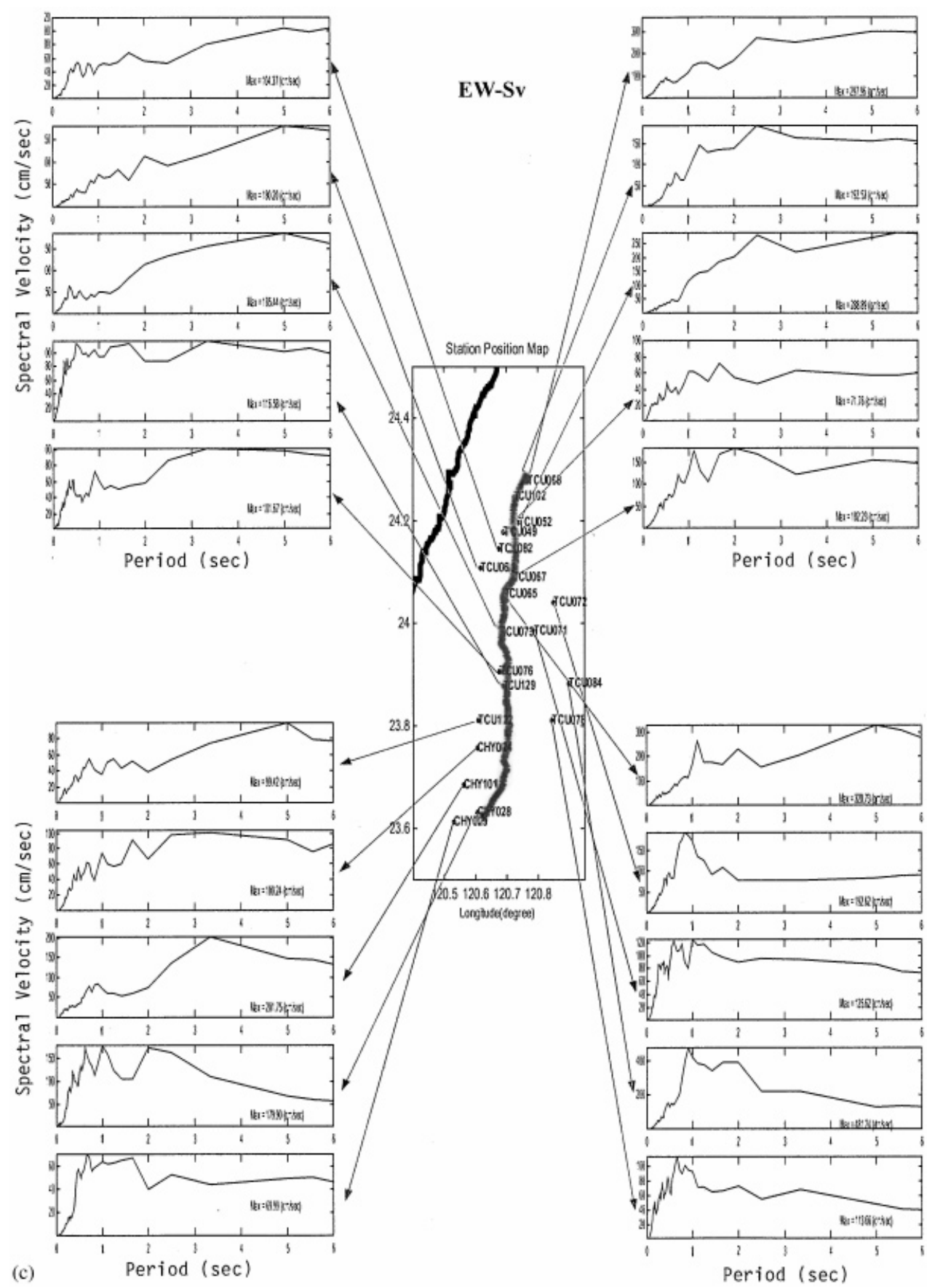

Figure 12. Continued. 


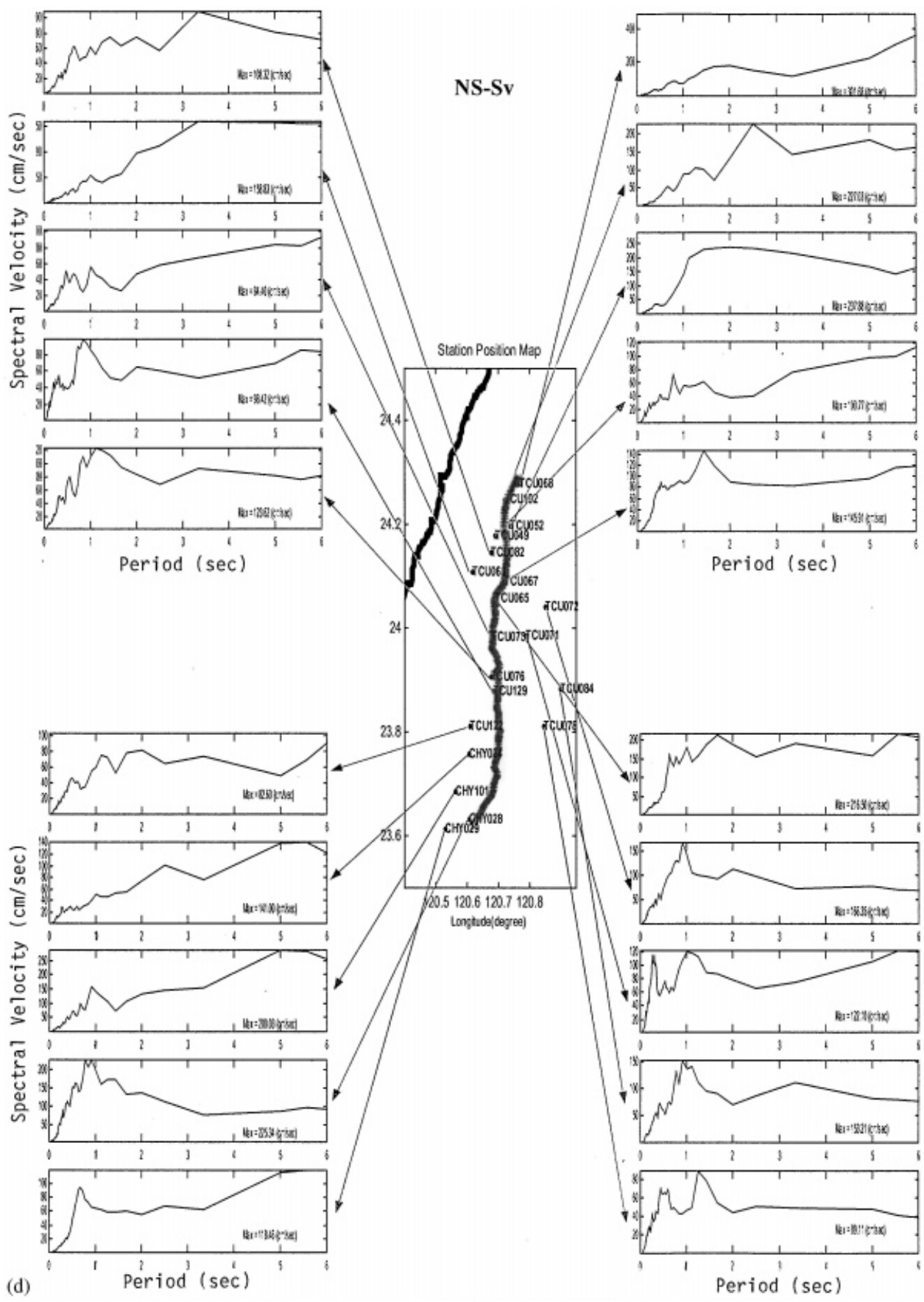

Figure 12. Continued. 

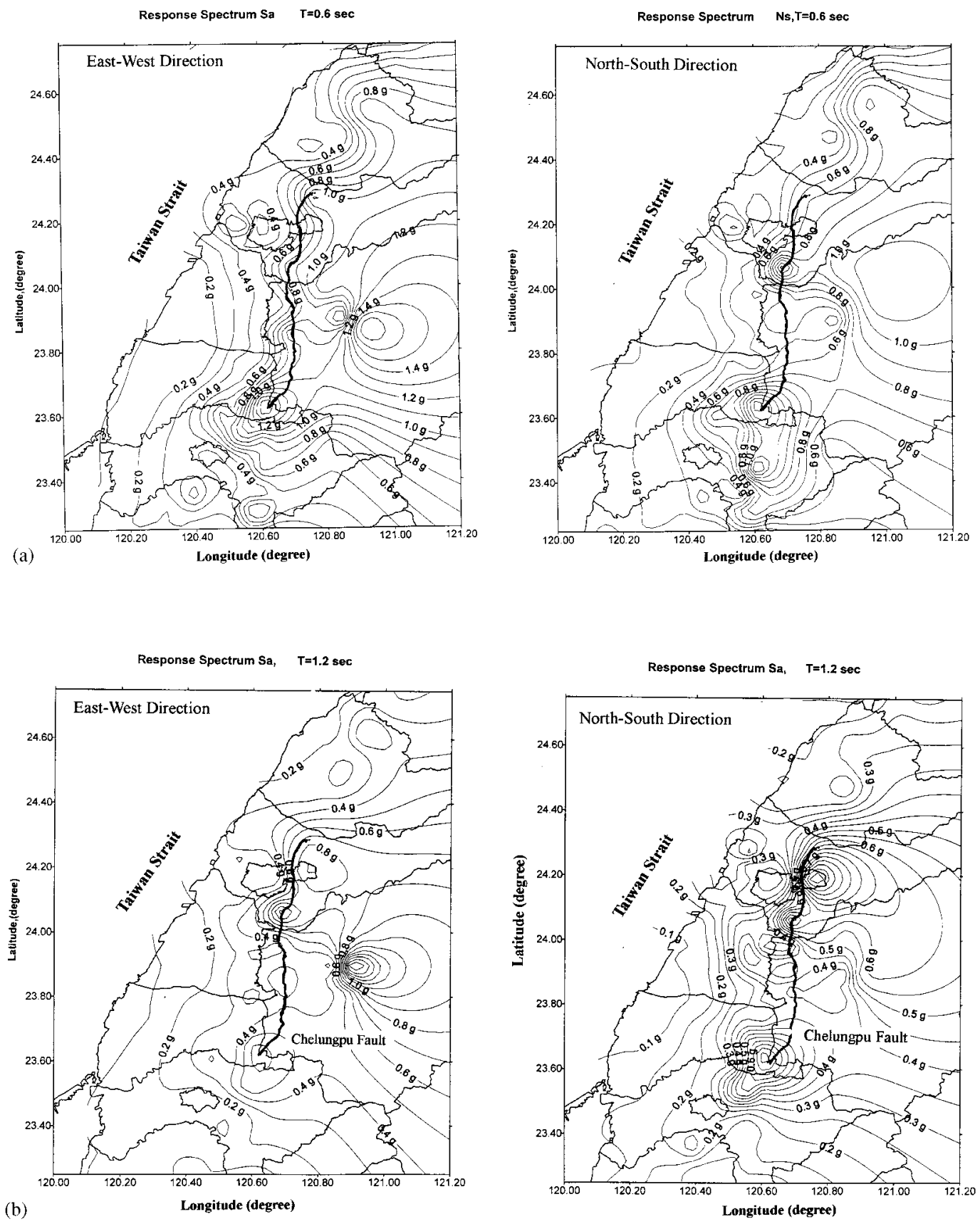

Figure 13. (a) Contour map of spectral acceleration Sa at $T=0.6 \mathrm{~s}$ along Chelungpu fault. (b) Contour map of spectral acceleration $\mathrm{Sa}$ at $T=1.2 \mathrm{~s}$ along Chelungpu fault. 

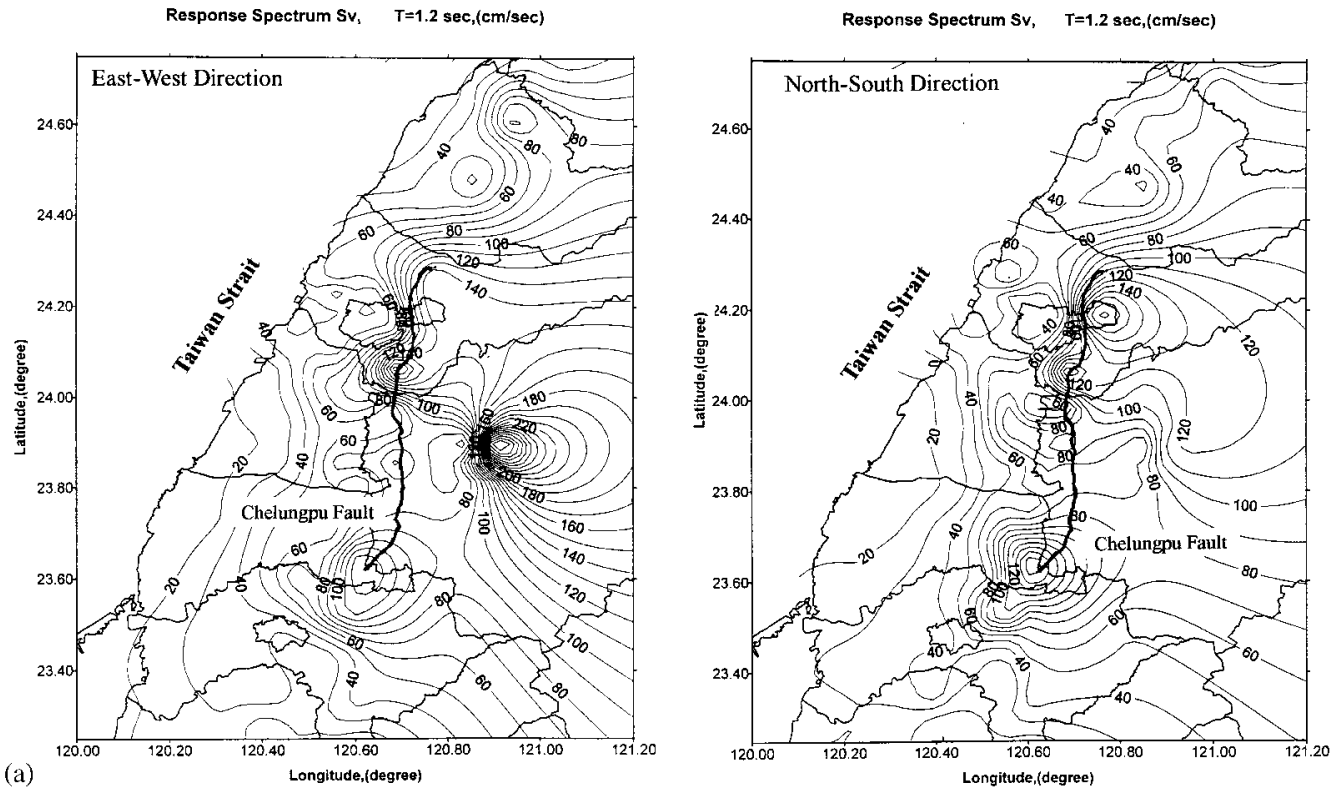

Response Spectrum Sv, $\quad T=4.0 \mathrm{sec},(\mathrm{cm} / \mathrm{sec})$

Response Spectrum Sv, T=4.0 sec, $(\mathrm{cm} / \mathrm{sec})$
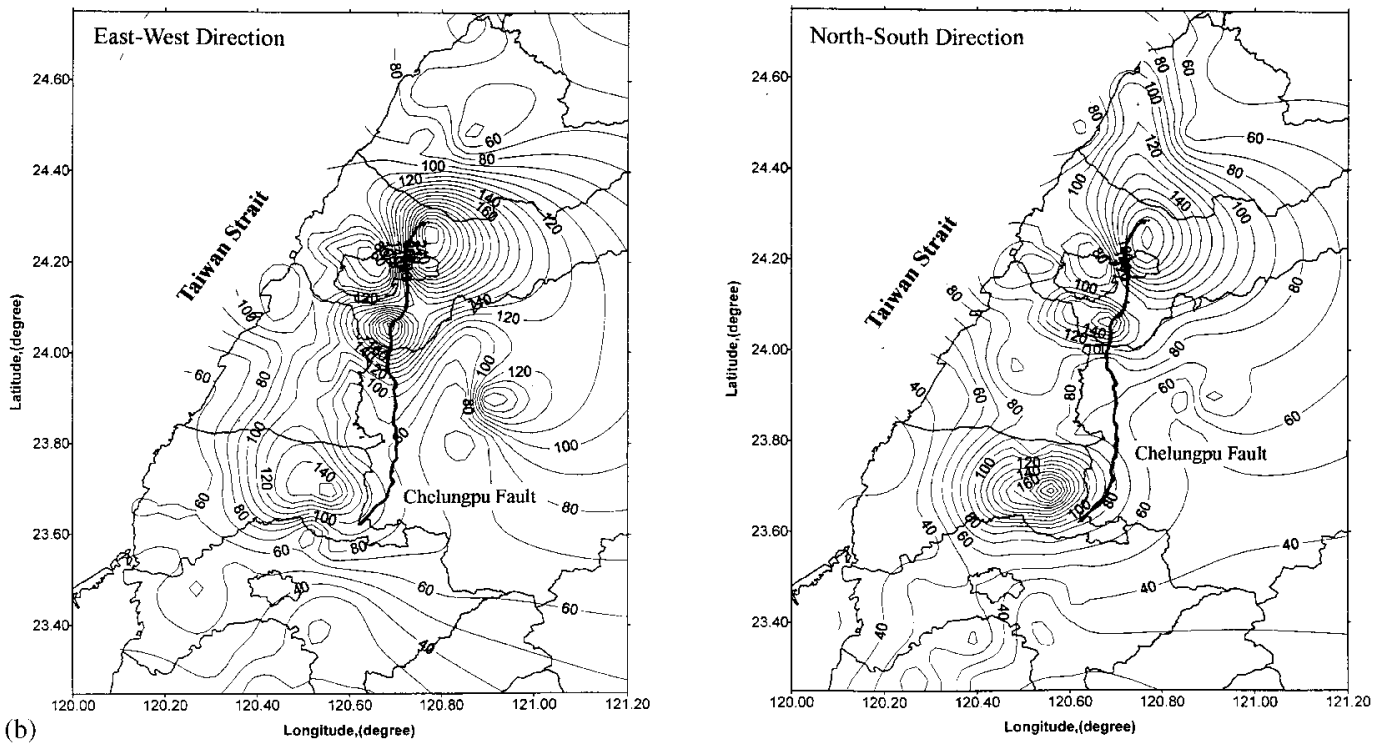

Figure 14. (a) Contour map of spectral velocity $S_{\mathrm{v}}$ at $T=1.2 \mathrm{~s}$ along Chelungpu fault. (b) Contour map of spectral velocity $S_{\mathrm{v}}$ at $T=4.0 \mathrm{~s}$ along Chelungpu fault. 

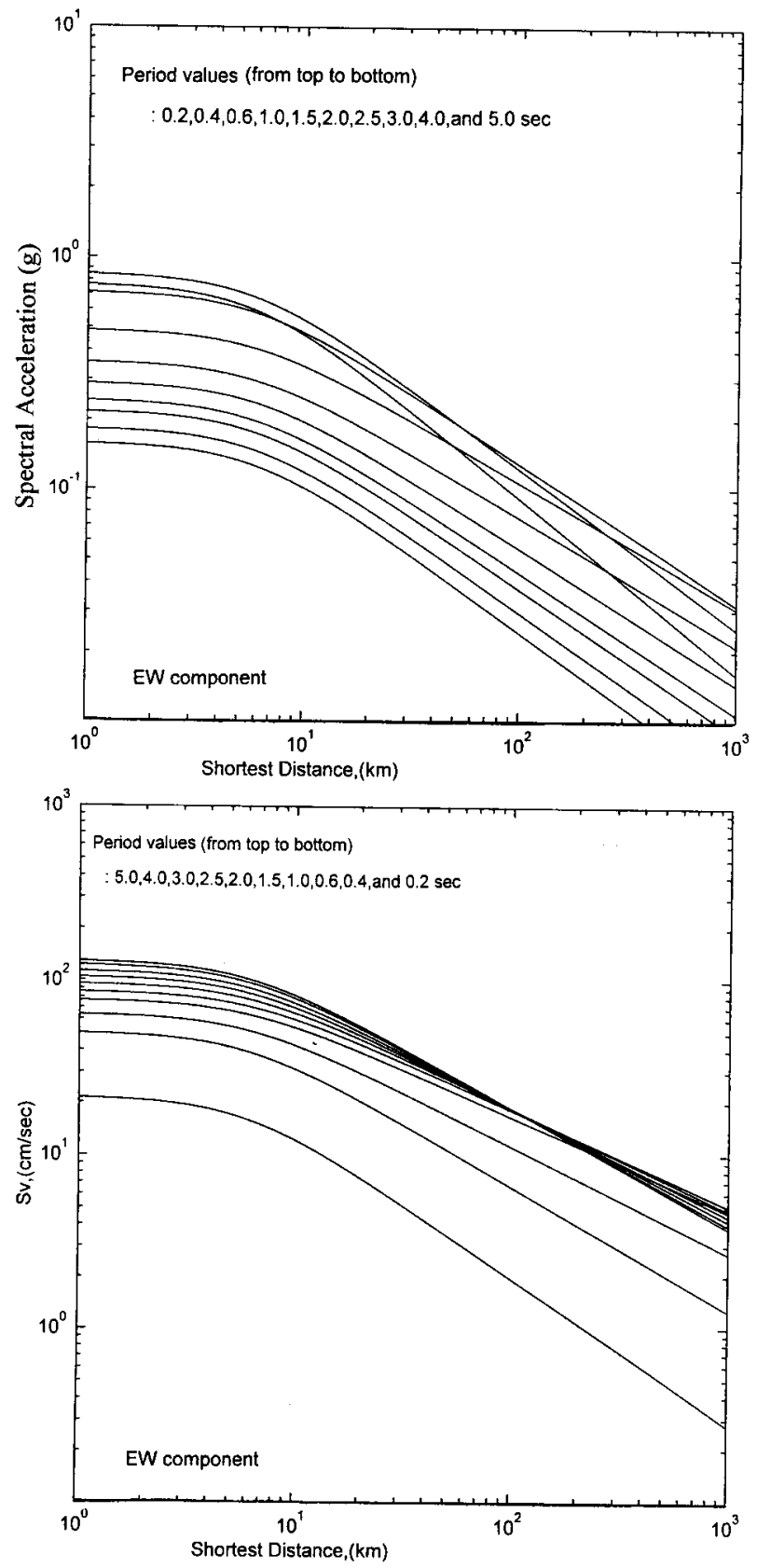

Figure 15. Spectral amplitude attenuation (both $S_{\mathrm{a}}$ and $S_{\mathrm{v}}$ ) from the Chi-Chi earthquake data (horizontal component). 
Table II. Identified model parameters of spectral amplitude attenuation form (east-west component of 921 Chi-Chi earthquake).

Spectral amplitude attenuation form

$$
=C_{1}+C_{2}(m-6)+\left[C_{4}+C_{5}(m-6)\right] \ln \left(R^{2}+C_{6}^{2}\right)^{1 / 2}
$$

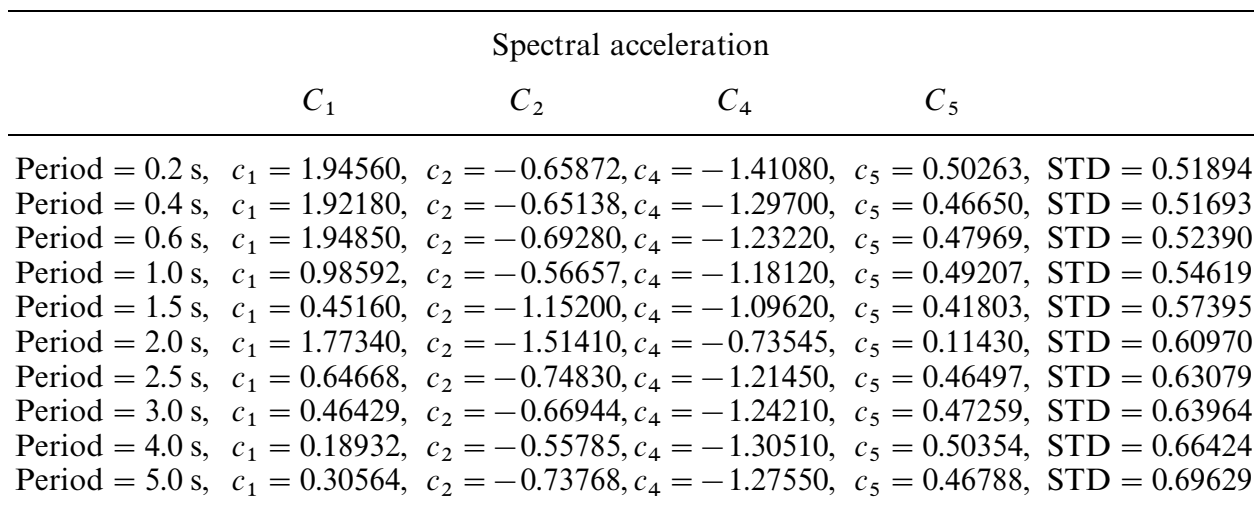

\section{Spectral velocity}

$\begin{array}{llll}C_{1} & C_{2} & C_{4} & C_{5}\end{array}$

\begin{tabular}{|c|c|c|c|}
\hline & $c_{1}=5.7637$, & $c_{2}=-0.91196, c_{4}=$ & $=0.38320, \mathrm{STD}=$ \\
\hline Period $=0.4 \mathrm{~s}$, & $c_{1}=6.3057$, & $c_{2}=-0.85197, c_{4}=-1.2500$ & $c_{5}=0.40801, \quad \mathrm{STD}=0.54224$ \\
\hline Period $=0.6 \mathrm{~s}$, & $c_{1}=6.0524$ & $c_{2}=-0.60943, c_{4}=-1.2246$ & $c_{5}=0.46696, \mathrm{STD}=0.52817$ \\
\hline Period $=1.0 \mathrm{~s}$, & $c_{1}=6.1241$, & $c_{2}=-0.62033, c_{4}=-1.2154$ & $c_{5}=0.51522, \quad \mathrm{STD}=0.54218$ \\
\hline Period $=1.5 \mathrm{~s}$, & $c_{1}=6.2302$, & $c_{2}=-0.60659, c_{4}=-1.1989$ & $c_{5}=0.49692, \mathrm{STD}=0.55695$ \\
\hline Period $=2.0 \mathrm{~s}$, & $c_{1}=6.3999$, & $c_{2}=-0.61395, c_{4}=-0.2108$ & $c_{5}=0.48253, \mathrm{~s}$ \\
\hline $\mathrm{d}=2.5 \mathrm{~s}$ & $c_{1}=6.4948$, & $c_{2}=-0.56989, c_{4}=-1.2733$ & $c_{5}=0.50490, \mathrm{STD}=0.58852$ \\
\hline $\mathrm{d}=3.0 \mathrm{~s}$, & $c_{1}=6.6239$, & $c_{2}=-0.57207, c_{4}=-1.2551$ & $c_{5}=0.47031, \quad \mathrm{STD}=0.59924$ \\
\hline$=4.0 \mathrm{~s}$ & $c_{1}=6.8046$ & $c_{2}=-0.60848, c_{4}=-1.3417$ & $c_{5}=0.51500, \mathrm{STD}=0.62485$ \\
\hline & $c_{1}=6.8913$, & $c_{2}=-0.61201, c_{4}=-1.3495$ & $c_{5}=0.50731, \mathrm{STD}=0.65067$ \\
\hline
\end{tabular}

where $Z$ is the design PGA value with $475 \mathrm{yrs}$ return period, $C$ is the elastic design spectrum, $\Omega=1.4$ is the over strength factor, $\alpha_{\mathrm{y}}$ is the structural related factor, $F_{\mathrm{u}}$ is the reduction factor, and $C / F_{u}$ can be defined as the yield base shear coefficient. $I$ and $W$ are the importance factor and the weight of the structure, respectively. Consider a structural system with period $T_{0}$. The $Z I\left(C / F_{u}\right)$ value can then be determined with the implementation of seismic design criteria of Taiwan Building Code. This value is equivalent to the yield strength factor $(\beta)$ defined from the analysis of Elastic-Perfect-Plastic SDOF system. For the inelastic response analysis of SDOF system the yield base shear $V_{\mathrm{y}}$ can be determined from the following equation:

$$
\left.Z I \frac{C}{F_{\mathrm{u}}}=\beta \text { (yield strength factor }\right)=\frac{V_{\mathrm{y}}}{m \cdot \ddot{x}_{\mathrm{g}, \max }}
$$

where $\ddot{x}_{\mathrm{g}, \max }$ is the maximum input PGA-value.

If a structure was designed with a dominant period $T_{0}$, and with a seismic zone factor of $Z=0.28 \mathrm{~g}$ (Zone-IB in Taiwan Building Code), the base-shear coefficient (similar to yield strength 


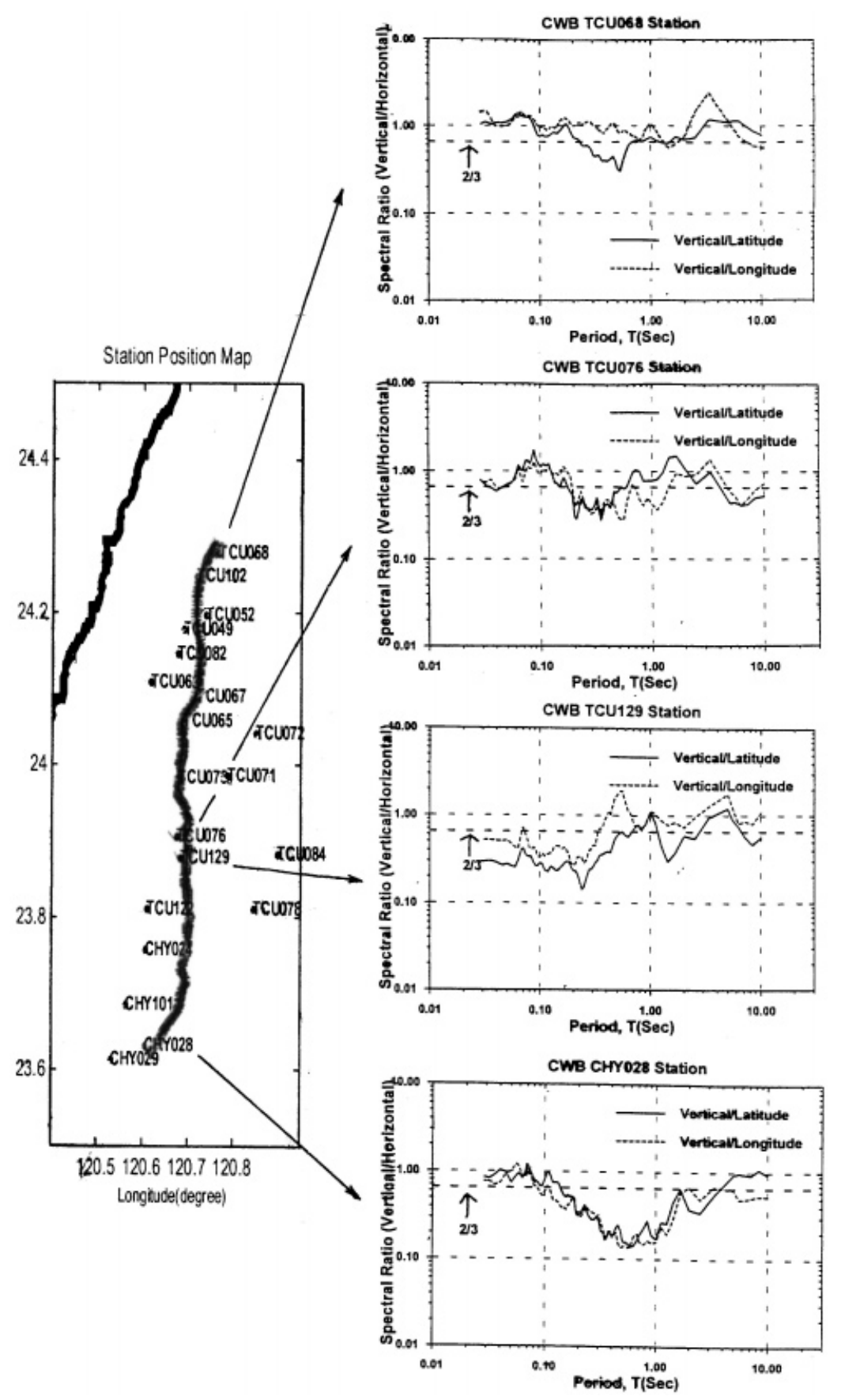

Figure 16. Vertical to horizontal spectral acceleration ratio at station: TCU068, TCU076, TCU129 and CHY028. 

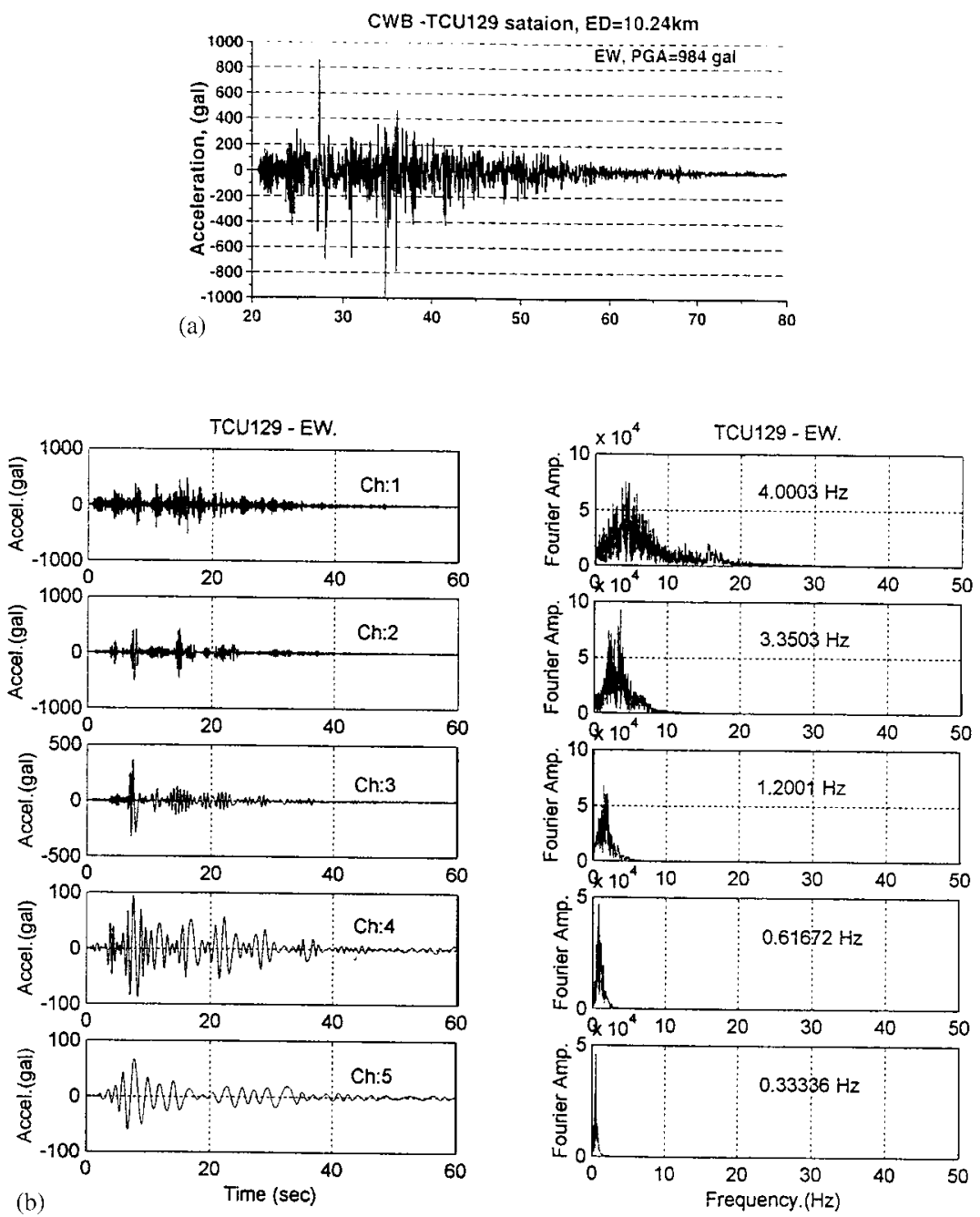

Figure 17. (a) Recorded ground acceleration at station: TCU129. (b) Intrinsic mode function decomposed from acceleration data at station TCU129 by using empirical mode decomposition method. The Fourier Amplitude of each IMF is also shown.

factor $\beta$ ) of the structural system can be estimated using the Taiwan Building Code. Based on Equation (9) the yield force $V_{\mathrm{y}}$ of the equivalent elastic-perfect-plastic (EPP) model can be determined using the same specified ductility ratio $\mu$. If the EPP-system was subjected to a specified ground motion (for example: the ground motion measured in Chi-Chi earthquake), the true ductility ratio of the system response can be estimated from the dynamic response analysis (using EPP model). Comparison can be made between the true system ductility and the designed ductility. Figure 19 shows the true system response ductility of the designed system (with 

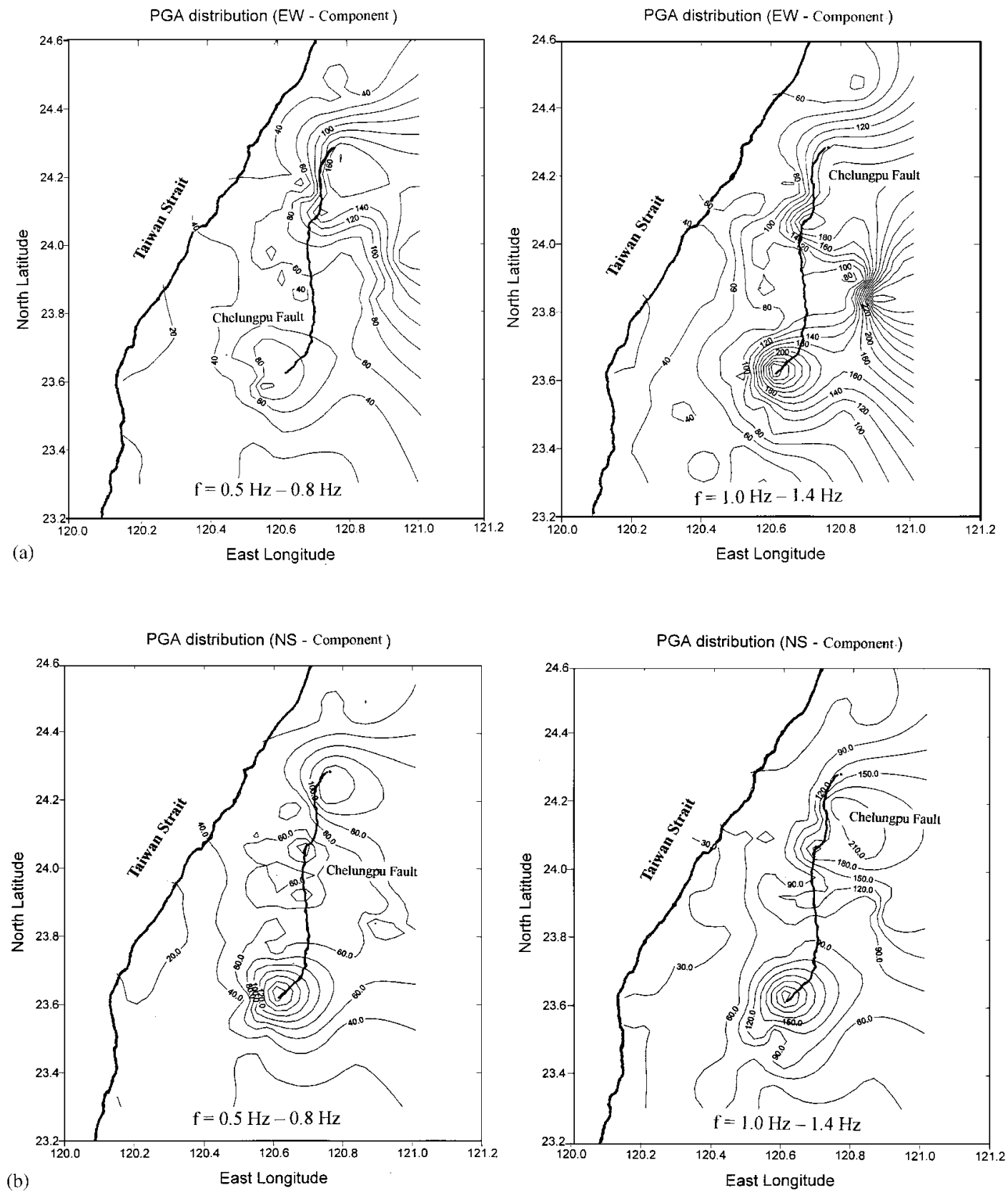

Figure 18. (a) Plot of contour map of PGA value from intrinsic mode function decomposed from ground motion data along Chelunpu fault (for frequency between $0.5-0.8 \mathrm{~Hz}$ and $1.0-1.4 \mathrm{~Hz}$ in east-west direction). (b) Plot of contour map of PGA value from intrinsic mode function decomposed from ground motion data along Chelunpu fault (for frequency between $0.5-0.8 \mathrm{~Hz}$ and $1.0 \mathrm{Ha}-1.4 \mathrm{~Hz}$ in north-south direction). 
a specified ductility ratio) subjected to input motion measured at station TCU129 and TCU068, respectively. It was found from this figure that for a structural system designed with short period the true response ductility ratio (subjected to the ground motion from TCU129 and TCU068) always exceed the code-specified (designed) ductility ratio and of course the structure will damage. To improve the system response subjected to such a near-field ground motion it is necessary to revise the seismic design code with the consideration of near-fault ground motion characteristics.

\section{CONCLUSIONS}

The 1999-9-21 Chi-Chi earthquake (Taiwan) with magnitude $M_{\mathrm{L}}=7.3$ provides a lot of nearfield ground motion data for the study of near fault ground motion and the structural response
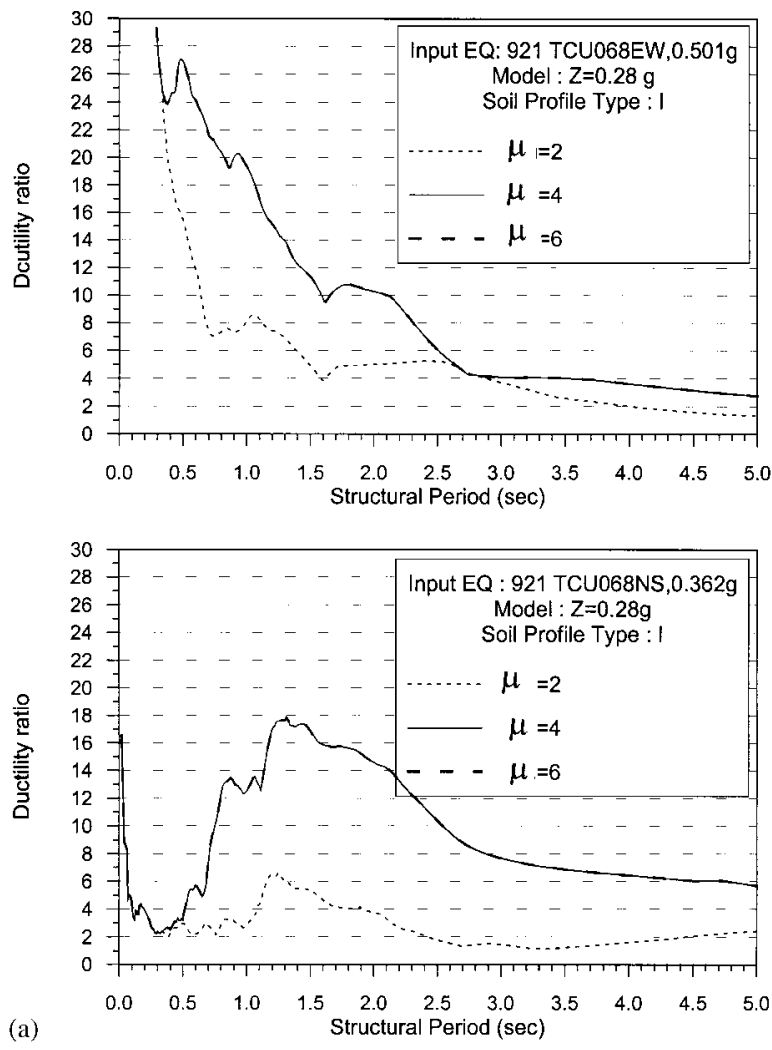

Figure 19. (a) Plot of ductility ratio with respect to structural period using ground motion data from TCU068. The system model parameters were determined from Taiwan Building Code (with $Z=0.28 \mathrm{~g}$, Soil type 1 and ductility ratio of 2, 4, and 6). (b) Plot of ductility ratio with respect to structural period using ground motion data from TCU129. The system model parameters were determined from Taiwan Building Code (with $Z=0.28 \mathrm{~g}$, Soil type 1 and ductility ratio of 2, 4, and 6). 

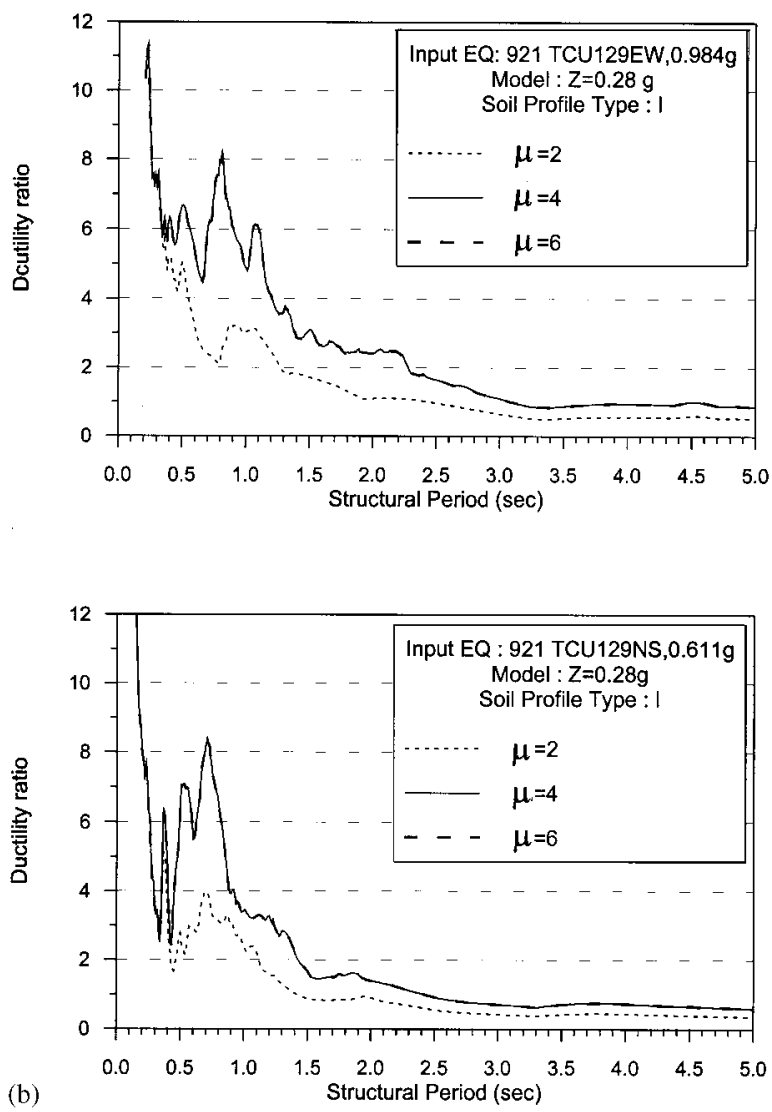

Figure 19. Continued.

subjected to such a near-field ground motion. From the preliminary analysis on ground motion data the following conclusions and recommendations are drawn:

(1) Based on the data collected near the Chelungpu fault a pulse-like wave was observed in the velocity data of free-field ground motion, particularly at both end of Chelungpu fault. The dominant period, $T_{\mathrm{p}}$, of the wave can be identified with period from $4 \mathrm{~s}$ to $8 \mathrm{~s}$, and a large velocity amplitude was also calculated. This pulse-like wave may cause significant damage to the structure.

(2) There are three records collected from this event with PGA-value greater than 980 gal. A large PGA-value was also observed at both ends of the Chelungpu fault as well as on the east side of the fault. Except the near-field ground acceleration the PGA attenuation of this earthquake did not show any particular feature as compared to the PGA attenuation form used previously in Taiwan (i.e. Equation (2)).

(3) For this particular earthquake large acceleration amplitude at low-frequency band $(f<0.4 \mathrm{~Hz})$ was observed (based on empirical mode decomposition analysis). A large 
spectral velocity $\left(S_{\mathrm{V}}\right)$ was also calculated in long structural period. This ground motion characteristic may be one of the features of near-field ground motion.

(4) The seismic demand of an inelastic SDOF system was studied using the ground motion data from this event. The displacement ductility of the non-linear SDOF system subjected to the near-field ground motion collected from this event was estimated. It is found that for a system with low ductility ratio the calculated base shear coefficient exceeded the codespecified value for system with almost all structures having different period.

\section{ACKNOWLEDGEMENTS}

The authors wish to express their thanks to Central Weather Bureau (CWB) for providing the Chi-Chi earthquake free-field ground motion data for this analysis. Suggestions on the paper contents given by Professor Anil K. Chopra (UCB) are also acknowledged.

\section{REFERENCES}

1. Wu FT. Recent tectonics of Taiwan. Journal of Physics of the Earth 1978; 26:256-299.

2. Tsai YB. Seismotectonics of Taiwan. Tectonophysics 1986; 125:17-37.

3. Hsu TL, Chang HC. Quaternary faulting in Taiwan. Memories of the Geological Society of China 1979; 3(2):155-165.

4. Shin TC. Chi-Chi earthquake - seismology. Proceedings of International Workshop on Chi-Chi Earthquake, Taichung, Taiwan, Dec.14-16, 1999;1-16.

5. Wesnousky SG. Earthquakes, quaternary faults, and seismic hazard in California. Journal of Geophysical Research 1986; 91(B12):12587-12631.

6. Somerville $\mathrm{P}$ et al. Characterizing crustal earthquake slip models for prediction of strong ground motion. Seismological Research Letters 1999; 70(1):59-80.

7. Hanks T, Kanamori H. A moment magnitude scale. Journal of the Geophysical Research 1979; 84:2348-2350.

8. Silvio KP, Wesnousky SG. Large earthquakes and crustal deformation near Taiwan. Journal of Geophysical Research 1989; 94(B6):7250-7264.

9. Makris N, Yiannis R. Rocking response and overturning of equipment under horizontal pulse-like motions. Earthquake Engineering Research Center, UC-Berkeley, PEER-1998/05, October, 1998.

10. Loh CH, Hwang CS, Jean YW. Seismic demand based on damage control model-considering basin effect and source effect. Soil Dynamics and Earthquake Engineering 1998; 17:335-345.

11. Loh CH, Penzien J, Tsai YB. Engineering analysis of SMART-1 seismic data. Earthquake Engineering and Structural Dynamics 1982; 10:575-591.

12. Huang NE, Sheng Z, Long SR, Wu MC, Shih HH, Zheng Q, Yeh NC. The empirical mode decomposition and the Hilbert spectrum for non-linear and non-stationary time series analysis. Proceedings of the Royal Society of London A 1998; 454:903-995. 